\title{
The Lectin Pathway in Thrombotic Conditions-A Systematic Review
}

\author{
${ }^{1}$ Centre for Haemophilia and Thrombosis, Department of Clinical \\ Biochemistry, Aarhus University Hospital, Aarhus, Denmark \\ ${ }^{2}$ Department of Anaesthesiology and Intensive Care Medicine, \\ Randers Regional Hospital, Randers, Denmark \\ ${ }^{3}$ Department of Clinical Medicine, Aarhus University, Aarhus, \\ Denmark
}

Julie Brogaard Larsen ${ }^{1} \quad$ Christine Lodberg Hvas ${ }^{2}$ Anne-Mette Hvas ${ }^{1,3}$

Address for correspondence Anne-Mette Hvas, MD, PhD,

\author{
Department of Clinical Biochemistry, Centre for Haemophilia and \\ Thrombosis, Aarhus University Hospital, Aarhus University, Palle Juul- \\ Jensens Boulevard 99, DK-8200 Aarhus N, Denmark \\ (e-mail: am.hvas@dadlnet.dk).
}

Thromb Haemost 2018;118:1141-1166.

\begin{abstract}
The lectin pathway of the complement system can activate the coagulation system in vitro, but the role of the lectin pathway in haemostatic activation and thrombosis in vivo is not clear. We performed a systematic review of the existing literature on associations between the lectin pathway and arterial and venous thrombosis, in accordance with the Assessing the Methodological Quality of Systematic Reviews guidelines. PubMed and Embase were searched from January 1990 to March 2017. We included original studies on human study populations investigating associations between the lectin pathway (protein serum levels, genotype or gene expression) and thrombotic conditions or laboratory coagulation markers. Exclusion criteria were case studies including fewer than five cases, conference abstracts or any other language than English. In total, 43 studies were included which investigated associations between the lectin pathway and cardiovascular thrombotic events (CVEs) $(n=22)$, ischaemic stroke $(n=9)$, CVE and stroke $(n=1)$ and other conditions (systemic lupus erythematosus [ $n=6$ ], sepsis-related coagulopathy $[n=3$ ], pulmonary embolism $[n=1]$, asparaginase treatment $[n=1])$. Studies on the lectin pathway and CVE risk reported discrepant results, as both high and low mannose-binding

Keywords

- lectin pathway

- complement proteins

- mannose-binding lectin

- thromboembolism

- blood coagulation lectin (MBL) serum levels were found to correlate with increased CVE risk. In ischaemic stroke patients, occurrence of stroke as well as increased stroke severity and poor outcome were consistently associated with high serum MBL. For other thromboembolic conditions, only few studies were identified. In conclusion, lectin pathway activation may negatively influence outcome after ischaemic stroke and possibly contribute to CVE risk. Further research is warranted to elucidate the role of the lectin pathway in other thrombotic conditions.
\end{abstract}

\section{Introduction}

Interplay between the immune system and haemostasis has long been recognized, ${ }^{1,2}$ and in recent years, interactions between the complement and coagulation systems have arisen as a field of considerable interest. ${ }^{3}$ The lectin pathway of the complement system is a relatively new player in this field, but increasing amounts of evidence support a crosstalk between lectin pathway proteins and coagulation, at least in vitro. ${ }^{4}$ Investigating these interactions more closely may improve our understanding of the pathogenesis of thrombosis in conditions with increased immunologic activation. received

October 26, 2017

accepted after revision

April 12, 2018 (c) 2018 Georg Thieme Verlag KG Stuttgart · New York
DOI https://doi.org/ 10.1055/s-0038-1654714. ISSN 0340-6245. 


\section{The Lectin Pathway}

The lectin pathway consists of the pattern recognition molecules mannose-binding lectin (MBL), ficolin-1, -2 and -3 (also named M-ficolin, L-ficolin and $\mathrm{H}$-ficolin) and collectins liver-1 and kidney-1 (CL-L1 and CL-K1), which circulate in complex with the MBL-associated serine proteases (MASP)- $1,-2$ and -3 . The activation of this pathway has been described in detail elsewhere. ${ }^{5,6}$ Briefly, the pattern recognition molecules bind to specific carbohydrate structures on microbial and cell surfaces, and this leads to MASP-1 and -2 activation and subsequent cleavage of $\mathrm{C} 4$ and $\mathrm{C} 2$, assembly of a $\mathrm{C} 3$ convertase and activation of the common complement pathway ( - Fig. 1). Besides, two other proteins, MAp44 (or MAP1) and MAp19 (or sMAP), bind to the pattern recognition molecules and are thought to exert a regulatory role in the lectin pathway. ${ }^{7}$ Activation of the lectin pathway contributes to the inflammatory response through activation of the common complement pathway and C5a generation. ${ }^{8} \mathrm{MBL}$ and ficolins also directly

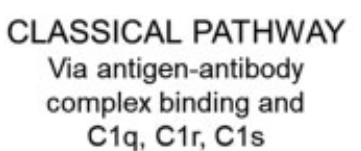

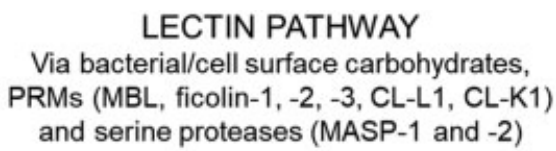

LECTIN PATHWAY Ms (MBL, ficolin-1, - 2, -3, CL-L1, CL-K1) and serine proteases (MASP-1 and -2)

\section{ALTERNATIVE PATHWAY Via $\mathrm{C} 3 \mathrm{~b}\left(\mathrm{H}_{2} \mathrm{O}\right)$ and factor $\mathrm{B}$}

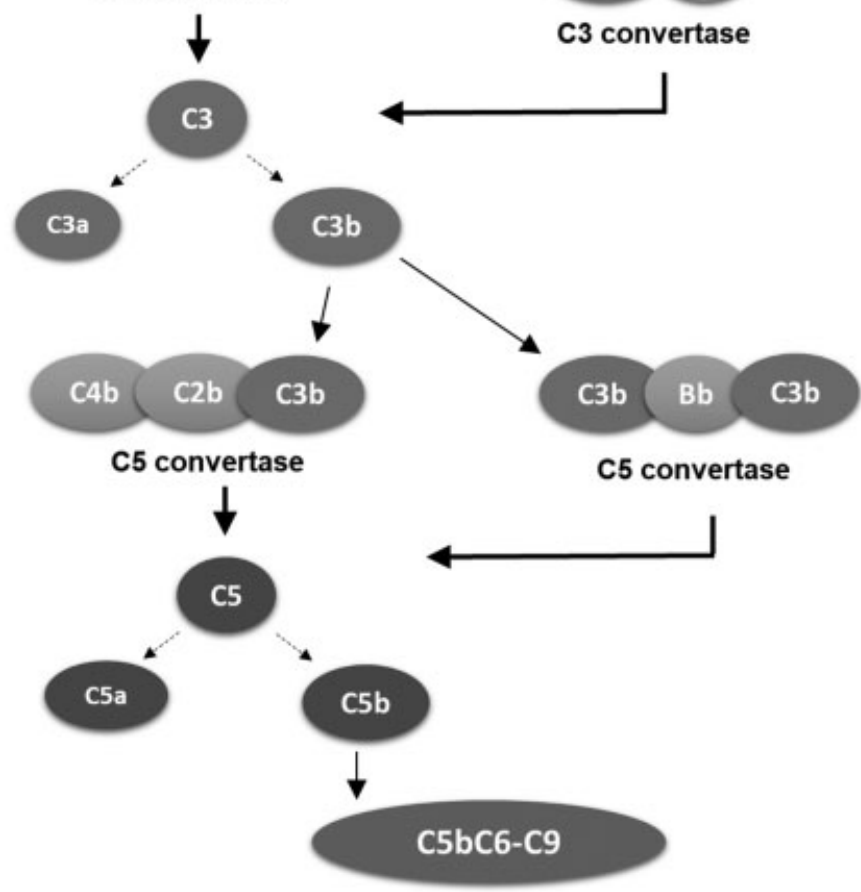

Membrane attack complex

Fig. 1 Lectin pathway activation. Lectin pathway activation is initiated by recognition of carbohydrate structures by the pattern-recognition molecules like (PRMs) mannose-binding lectin (MBL), ficolins 1-3 and collectin liver-1 (CL-L1) and kidney-1 (CL-K1), which circulate in complex with the MBL-associated serine proteases (MASPs). The binding activates MASPs and causes the subsequent cleaving of complement factors (C) 2 and 4 . This generates the split products $C 2 \mathrm{~b}$ and $\mathrm{C} 4 \mathrm{~b}$, which aggregate to form the $\mathrm{C} 3$ convertase complex. Cleavage of $\mathrm{C} 3$ further leads to the generation of $\mathrm{C} 5$ convertase ( $\mathrm{C} 4 \mathrm{~b} \mathrm{C} 2 \mathrm{bC} 3 \mathrm{~b}$ complex), $\mathrm{C} 5 \mathrm{~b}$ production and formation of the terminal membrane attack complex on the surface of the microbe or cell. Dark arrows denote enzymatic activity; dashed arrows denote assembly of split products into active complexes. 
interact with C-reactive protein and pentraxin-3, ${ }^{9-12}$ contribute to pathogen opsonization ${ }^{13,14}$ and stimulate a proinflammatory cytokine response. ${ }^{15}$ Moderate increases in lectin pathway protein serum concentrations have been described during the acute phase response, although these findings contrast to some degree. ${ }^{16-20}$

\section{Associations between Lectin Pathway Protein Levels and Disease}

Serum levels of lectin pathway proteins show considerable inter-individual variation, particularly the MBL. ${ }^{21}$ The genetic background for this variation, as well as possible associations between low serum levels and increased sus- ceptibility to disease, have been investigated during the years. Some polymorphisms are consistently associated with either higher or lower serum protein levels and with increased disease risk, while such associations are less clear for other polymorphisms. - Table 1 provides an overview of the most commonly described lectin pathway gene polymorphisms and of some clinical conditions associated with lower or deficient lectin pathway protein levels.

Around $10 \%$ of the general population have low serum MBL levels. ${ }^{22}$ The clinical importance of this is still discussed; but it is well established that MBL deficiency is a risk factor for infection in susceptible populations. ${ }^{23-26}$ However, the exact role of serum MBL levels in infection and the

Table 1 Associations between lectin pathway gene polymorphisms, serum concentrations and disease risk

\begin{tabular}{|c|c|c|}
\hline $\begin{array}{l}\text { Protein } \\
\text { Corresponding } \\
\text { gene }\end{array}$ & $\begin{array}{l}\text { Known mutations or polymorphisms leading to } \\
\text { altered serum concentration or function }\end{array}$ & $\begin{array}{l}\text { Diseases or increased risk of disease associated } \\
\text { with lower or deficient serum concentration or } \\
\text { function }\end{array}$ \\
\hline $\begin{array}{l}\text { MBL } \\
\text { MBL2 }\end{array}$ & 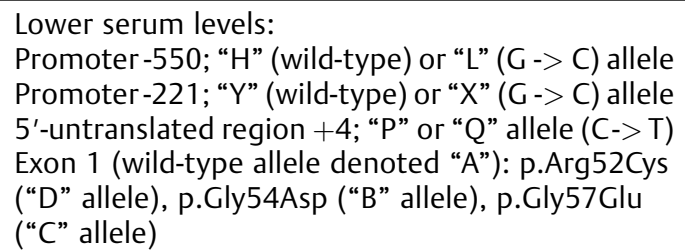 & $\begin{array}{l}\text { Deficiency: } \\
\text { Bronchiectasia }{ }^{129} \text { and increased infection risk in } \\
\text { vulnerable populations, e.g. neonates }{ }^{130} \text { and } \\
\text { chemotherapy-treated patients }{ }^{131,132} \\
\text { Worse outcome in pneumonia } \\
\text { Increased risk of spontaneous recurrent } \\
\text { abortion }{ }^{134-136}\end{array}$ \\
\hline $\begin{array}{l}\text { Ficolin-1 } \\
\text { FCN1 }\end{array}$ & $\begin{array}{l}\text { Higher serum levels: } \\
\text { Promoter }-542 \mathrm{G}>\mathrm{A} \text { and }-144 \mathrm{C}>\text { A variants } \\
\text { Lower serum levels: } \\
\text { p.Ala218Thr, p.Asn289Ser, p.Ser268Pro }\end{array}$ & $\begin{array}{l}\text { Promoter }-542 \text { and }-144 \text { variants associated with } \\
\text { worse outcome in systemic inflammation and } \\
\text { leprosy } 137,139\end{array}$ \\
\hline $\begin{array}{l}\text { Ficolin-2 } \\
\text { FCN2 }\end{array}$ & $\begin{array}{l}\text { Higher levels: } \\
\text { Promoter -602G }>\text { A, promoter } 4 A>G^{140} \\
\text { Lower levels: } \\
\text { Promoter -986A }>\text { G, p.Ala258Ser }{ }^{140}\end{array}$ & Common variable immunodeficiency ${ }^{29}$ \\
\hline $\begin{array}{l}\text { Ficolin-3 } \\
\text { FCN3 }\end{array}$ & Deficiency: p.Leu117-frameshift (+1637DelC) ${ }^{28}$ & $\begin{array}{l}\text { Pneumonia, bronchiectasia, }{ }^{28,29} \text { and necrotising } \\
\text { enterocolitis }\end{array}$ \\
\hline $\begin{array}{l}\text { CL-L1 } \\
\text { COLEC10 }\end{array}$ & $\begin{array}{l}\text { Higher serum levels: p.Arg125Trp } \\
\text { Deficiency: } \\
\text { p.Arg9Ter, p.Cys176Trp, p.Gly77Glu-frameshift }{ }^{33}\end{array}$ & Deficiency: 3MC syndrome ${ }^{33}$ \\
\hline $\begin{array}{l}\text { CL-K1 } \\
\text { COLEC11 }\end{array}$ & $\begin{array}{l}\text { Lower serum levels: } \\
\text { p.Arg216His exon } 8 \text { variant: G/G and G/A variants } \\
\text { associated with lower CL-K1 levels than A/A var- } \\
\text { iant, }{ }^{142} \text { promoter }-9570 C>T^{141} \\
\text { Deficiency: } \\
\text { p.Ser169Pro, p.Gly204Ser, p.Ser217del, p.Phe16- } \\
\text { Ser-frameshift, p.Gly101Val-frameshift, exon 1-3 } \\
\text { deletion, }{ }^{34} \text { p.Asp30Ala-frameshift, p.Gly104Val- } \\
\text { frameshift, p.Ala126Thr }{ }^{33}\end{array}$ & $\begin{array}{l}\text { Tuberculosis }^{143} \\
\text { Schistosomiasis infection } \\
\text { Deficiency: } 3 M C \text { syndrome } \\
\text { D3,34 }\end{array}$ \\
\hline $\begin{array}{l}\text { MASP-1, MASP-3 } \\
\text { and MAp44 } \\
\text { MASP1 }\end{array}$ & $\begin{array}{l}\text { Deficiency: } \\
\text { p.His497Tyr, p.Cys630Arg, p.Gly666Glu, }{ }^{34} \text { p. } \\
\text { Trp3Ter, }{ }^{33} \text { p.Gly687Arg, p.Trp290Ter }{ }^{35}\end{array}$ & Deficiency: $3 M C$ syndrome ${ }^{33-35}$ \\
\hline $\begin{array}{l}\text { MASP-2 and } \\
\text { MAp19 } \\
\text { MASP2 }\end{array}$ & $\begin{array}{l}\text { Lower levels: } \\
\text { Asp120Gly, Pro126Leu, His155Arg, Val377Ala, } \\
\text { Arg439His, dupCys-His-Asn-His in c.466 (reviewed } \\
\text { by Beltrame et al }{ }^{144} \text { ) } \\
\text { p.Asp120Gly associated with impaired binding to } \\
\text { MBL/ficolins } 145,146\end{array}$ & $\begin{array}{l}\text { Lower levels: Symptomatic Chagas' disease, }{ }^{31} \\
\text { lepromatous leprosy } \\
\text { p.Asp120Gly: Association with disease } \\
\text { uncertain }\end{array}$ \\
\hline
\end{tabular}

Abbreviations: MAp19, MBL-associated protein of 19 kD; MAp44, MBL-associated protein of 44 kD; MASP, MBL-associated protease; MBL, mannosebinding lectin.

Note: $3 \mathrm{MC}$ syndrome: Mingarelli, Malpuech, Michels and Carnevale syndrome, characterized by craniofacial abnormalities, developmental delay and intellectual disability. 
development of sepsis is not completely understood, as reviewed recently by Charchaflieh et al. ${ }^{27}$ Only few cases of ficolin ${ }^{28-30}$ and MASP-2/Map19 deficiency ${ }^{31,32}$ have been described, while CL-L1 and CL-K1 and MASP-1/-3 deficiency is consistently associated with a developmental syndrome (the 3MC syndrome), ${ }^{33-35}$ indicating a role for lectin pathway proteins in embryonal development. Besides decreased resistance towards infection in patients with low lectin pathway protein serum levels, there is also a growing interest for the contribution of the lectin pathway to other inflammatory conditions, and for associations between higher serum levels and disease risk. This includes autoimmune diseases, such as rheumatoid arthritis and systemic lupus erythematosus (SLE). Associations between MBL and disease severity $^{36}$ and mortality ${ }^{37}$ in rheumatoid arthritis are described, and Ammitzboll et al found increased levels of M-ficolin in synovial fluid in rheumatoid arthritis. ${ }^{38}$ However, a recent meta-analysis found no association between MBL2 genotype and occurrence of rheumatoid arthritis. ${ }^{39}$ Higher levels of lectin pathway proteins were recently demonstrated in SLE patients, ${ }^{40}$ and ficolin- 1 was associated with disease severity in SLE. ${ }^{41}$ More recently, the lectin pathway has also been associated with metabolic diseases with inflammatory components, such as diabetes ${ }^{42,43}$ and atherosclerosis, ${ }^{44,45}$ and some studies also reported increased levels of serum MBL in cancer. ${ }^{46-48}$ Thus, there is evidence that the lectin pathway may be involved not only in defence against pathogens but in a broad range of clinical conditions.

\section{Associations between Lectin Pathway Proteins and Coagulation}

Several studies have investigated associations between the lectin pathway and coagulation in vitro. An overview is presented in - Table 2 and - Fig. 2. MASP-1 and -2 show affinity for a range of substrates, and MASP-1 shares similarities with prothrombin and MASP-2 with coagulation factor (F)Xa. ${ }^{49-51}$ Recombinant (r) active MASP-1 can cleave fibrinogen, demonstrated by the generation of fibrinopeptides $A$ and $B$ and fibrin $\gamma_{2}-$ and $\alpha_{n}$ chains, ${ }^{52,53}$ and activate FXIII. ${ }^{52-54}$ Thus, MASP-1 induces fibrin formation and crosslinking in vitro. Furthermore, Hess et al also found that rMASP-1 generated active thrombin-activatable fibrinolysis inhibitor and prolonged clot lysis time in a plasma-based assay. ${ }^{53}$ This indicates that MASP-1 also attenuates fibrinolysis. Also, serum-derived MBL-MASP complexes were found to cleave fibrinogen and activate FXIII. ${ }^{55}$ Recently, it was demonstrated that MASP-1 also cleaves prothrombin and gives rise to what appeared to be active thrombin. ${ }^{56}$ MASP-1 shortened thromboelastography clotting time and clot formation time in healthy whole blood and plasma ${ }^{57}$ as well as clot formation time in a micro-vascular flow model under shear stress, ${ }^{58}$ while MASP-1 inhibition in the same flow model delayed the time to clot formation. ${ }^{58}$ The ability to cleave prothrombin and generate active thrombin has also been demonstrated for rMASP-2 and MBL-MASP-2 complexes. ${ }^{59}$ Notably, for both MASP-1 and MASP-2, cleavage of coagulation proteins and clot formation happened at a lower rate than FXa- and/or thrombin-induced cleavage, ${ }^{52,59}$ and MASP-1- and thrombin-induced clots were also found to differ in density and structure. ${ }^{53}$

There is evidence that the coagulation system can activate the lectin pathway in turn. Endo et al demonstrated that murine ficolin and MBLs bind to fibrinogen and fibrin, and that fibrinogen induces lectin pathway activation in mouse serum. ${ }^{60}$ Kozarcanin et al showed that ficolins are capable of binding to the surface of activated platelets, and that fibrin binds MASPs and induce MASP-C1-inhibitor or MASP-antithrombin complex formation, indicating MASP activation. ${ }^{61}$ Finally, Keizer et al found that tissue factor pathway inhibitor, an endogenous inhibitor of coagulation, can bind and inhibit MASP-2 activation. ${ }^{62}$ Thus, crosstalk between the lectin pathway and coagulation occurs at several points, and interactions between lectin pathway proteins and coagulation could contribute to hypercoagulability and increased thrombosis risk in a range of clinical conditions. Our aim was to systematically review the existing literature on associations between the lectin pathway and thrombotic conditions in humans.

\section{Materials and Methods}

The present systematic review was conducted in accordance with the Assessing the Methodological Quality of Systematic Reviews guidelines. ${ }^{63}$ The protocol was published in the PROSPERO database (reg. no. CRD42017070207, www.crd. york.ac.uk/prospero).

\section{Literature Search}

PubMed and Embase were searched from 1 January 1990 to 29 March 2017. No additional filters were set. Free-text as well as MeSH terms/Emtree-preferred terms were used. Keywords and search combinations were as follows:

\section{PubMed}

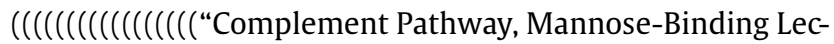
tin”[Mesh]) OR “Mannose-Binding Lectin”[Mesh]) OR “Mannose-Binding Protein-Associated Serine Proteases"[Mesh]) OR "ficolin" [Supplementary Concept]) OR “lectin pathway") OR "lectin pathway activation") OR "mannose-binding lectin") OR "mannan-binding lectin") OR "mannose-binding lectin associated serine protease") OR "mannose-binding lectin associated serine proteases") OR "map19") OR "map44”) OR “collectin 11") OR “collectin 10") OR ficolin*))

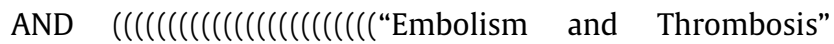
[Mesh])) OR "Myocardial Ischemia"[Mesh]) OR "Stroke" [Mesh]) OR "Mesenteric Vascular Occlusion"[Mesh]) OR "Renal Artery Obstruction"[Mesh]) OR "Peripheral Arterial Disease"[Mesh]) OR “Disseminated Intravascular Coagulation"[Mesh]) OR ("Blood Coagulation"[Mesh])) OR "Platelet Activation"[Mesh]) OR "blood coagulation") OR "platelet activation") OR "arterial thrombosis") OR "venous thrombosis") OR "venous thromboembolism") OR "disseminated intravascular coagulation") OR "myocardial infarction") OR "cardiovascular disease") OR "ischemic stroke") OR "hemorrhagic stroke") OR "renal artery thrombosis") OR 
Table 2 Overview of studies investigating associations between the lectin pathway and coagulation in vitro

\begin{tabular}{|c|c|c|c|}
\hline $\begin{array}{l}\text { Author, } \\
\text { year }\end{array}$ & LP protein & $\begin{array}{l}\text { Research question addressed } \\
\text { Coagulation protein or activation assay }\end{array}$ & Findings \\
\hline $\begin{array}{l}\text { Jenny et } \mathrm{al}^{58} \\
2018\end{array}$ & rMASP-1 & $\begin{array}{l}\text { Influence of MASP-1 and inhibition of } \\
\text { MASP- } 1 \text { on blood clot formation } \\
\text { Whole blood, micro-vascular flow model }\end{array}$ & $\begin{array}{l}\text { MASP-1 addition accelerates clot formation } \\
\text { while inhibition of MASP-1 prolongs time to } \\
\text { clot formation }\end{array}$ \\
\hline $\begin{array}{l}\text { Kozarcanin } \\
\text { et al }{ }^{61} \\
2016\end{array}$ & $\begin{array}{l}\text { MASP-1 and }-2 \text {, } \\
\text { ficolins, MBL }\end{array}$ & $\begin{array}{l}\text { Ability of coagulation factors and platelets } \\
\text { to activate MASPs } \\
\text { Platelets, fibrin } \\
\text { LP-platelet binding assessed with flow } \\
\text { cytometry }\end{array}$ & $\begin{array}{l}\text { Activated platelets bind ficolin-1, }-2 \text { and }-3 \\
\text { on surface } \\
\text { Fibrin and fibrin d-dimer bind MASP-1 and }-2 \\
\text { and induce MASP-C1inh/-anti-thrombin } \\
\text { complex formation }\end{array}$ \\
\hline $\begin{array}{l}\text { Jenny et al } \\
2015\end{array}$ & rMASP-1 & $\begin{array}{l}\text { Influence of MASP-1 addition on blood clotting } \\
\text { Thromboelastography; whole blood, platelet- } \\
\text { poor plasma, purified fibrinogen solution } \\
\text { Prothrombin }\end{array}$ & $\begin{array}{l}\text { MASP-1 addition shortens thromboelasto- } \\
\text { graphy clotting time and clot formation } \\
\text { time in the presence of prothrombin }\end{array}$ \\
\hline $\begin{array}{l}\text { Jenny et al } \\
2015\end{array}$ & rMASP-1 & $\begin{array}{l}\text { Ability of MASP-1 to cleave wild-type or } \\
\text { mutant prothrombin; characterization of } \\
\text { cleavage sites and products } \\
\text { Prothrombin (wild-type or mutant at cleav- } \\
\text { ing sites R271, R320, R393) }\end{array}$ & $\begin{array}{l}\text { MASP- } 1 \text { cleaves prothrombin at R271 and } \\
\text { R393 and gives rise to active thrombin } \\
\text { species }\end{array}$ \\
\hline $\begin{array}{l}\text { Keizer } \\
\text { et } \mathrm{al}^{62} \\
2015\end{array}$ & $\begin{array}{l}\text { rMASP-2; } \\
\text { LP activation } \\
\text { (C4 deposition) }\end{array}$ & $\begin{array}{l}\text { Ability of TFPI to inhibit MASP-2; character- } \\
\text { ization of inhibitory domain } \\
\text { Tissue factor pathway inhibitor (TFPI) }\end{array}$ & $\begin{array}{l}\text { TFPI (Kunitz-2 domain) inhibits rMASP-2 } \\
\text { activity (chromogenic assay) and human } \\
\text { serum LP activation }\end{array}$ \\
\hline $\begin{array}{l}\text { Hess et al } \\
2012\end{array}$ & rMASP-1 & $\begin{array}{l}\text { Ability of MASP-1 to activate coagulation } \\
\text { and inhibit fibrinolysis } \\
\text { Clot formation and lysis assay, prothrombin } \\
\text { fragment } 1+2 \text {, fibrinopeptide A, thrombin- } \\
\text { activatable fibrinolysis inhibitor, FXIII activation } \\
\text { Citrated plasma and purified fibrinogen and } \\
\text { FXIII (human) }\end{array}$ & $\begin{array}{l}\text { MASP-1 activates FXIII, induces generation } \\
\text { of prothrombin fragment } 1+2 \text { and fibri- } \\
\text { nopeptide } A \text {, activates thrombin-activatable } \\
\text { fibrinolysis inhibitor and prolongs clot lysis }\end{array}$ \\
\hline $\begin{array}{l}\text { Endo et } \mathrm{al}^{60} \\
2010\end{array}$ & $\begin{array}{l}\text { rFicolin } A, \text { rMBL- } \\
\text { A, rMBL-C } \\
\text { (mouse) } \\
\text { LP activation } \\
\text { (C4 deposition) }\end{array}$ & $\begin{array}{l}\text { Ability of fibrinogen/fibrin to bind ficolin and } \\
\text { MBL and to activate LP } \\
\text { Fibrinogen and fibrin (human) }\end{array}$ & $\begin{array}{l}\text { Murine ficolin and MBL binds to fibrinogen } \\
\text { (A } \alpha \text { and } B \beta \text { chains) and fibrin ( } \alpha \text { and } \beta \text { chains) } \\
\text { in dose-dependent manner } \\
\text { Fibrinogen induces LP activation in mouse } \\
\text { serum }\end{array}$ \\
\hline $\begin{array}{l}\text { Skjoedt } \\
\text { et al }{ }^{149} \\
\text { (conference } \\
\text { abstract) }\end{array}$ & MAp44 & $\begin{array}{l}\text { Ability of MAp44 to inhibit platelet function } \\
\text { and coagulation } \\
\text { Platelet activation and aggregation, } \\
\text { whole blood clotting, fibrin clot formation } \\
\text { and lysis in plasma (human) }\end{array}$ & $\begin{array}{l}\text { MAp44 attenuates platelet activation and } \\
\text { aggregation, clot amplitude in whole blood } \\
\text { (intrinsic pathway) and fibrin clot formation }\end{array}$ \\
\hline $\begin{array}{l}\text { Gulla et } \mathrm{al}^{55} \\
2010\end{array}$ & $\begin{array}{l}\text { Ficolin- or MBL- } \\
\text { MASP-1/-2 com- } \\
\text { plexes (serum- } \\
\text { derived) }\end{array}$ & $\begin{array}{l}\text { Ability of ficolin-/MBL-MASP complexes to } \\
\text { activate coagulation } \\
\text { Fibrin clot formation in citrated plasma and } \\
\text { purified fibrinogen/FXIII solution (human) }\end{array}$ & $\begin{array}{l}\text { Ficolin-/MBL-MASP complexes induces FXIII } \\
\text { activation and fibrinogen cleavage in puri- } \\
\text { fied systems and clot formation in plasma }\end{array}$ \\
\hline $\begin{array}{l}\text { Krarup } \\
\text { et } \mathrm{al}^{52} \\
2008\end{array}$ & rMASP-1 & $\begin{array}{l}\text { Ability of MASP-1 to cleave coagulation } \\
\text { proteins } \\
\text { Fibrinogen, FXIII (human) }\end{array}$ & $\begin{array}{l}\text { MASP-1 cleaves FXIII (presence of activated } \\
\text { A-chain) and fibrinogen (presence of } \\
\text { Y-chains and fibrinopeptide B) but at a } \\
\text { significantly lower rate than thrombin }\end{array}$ \\
\hline $\begin{array}{l}\text { Krarup } \\
\text { et al } \\
2007\end{array}$ & $\begin{array}{l}\text { rMASP-2, } \\
\text { rMBL-A-MASP-2 } \\
\text { complexes (rat) }\end{array}$ & $\begin{array}{l}\text { Ability of MASP-2 to cleave and activate } \\
\text { prothrombin } \\
\text { Prothrombin, thrombin activity } \\
\text { (VPR-AMC turnover), fibrin formation } \\
\text { (turbidimetry, }{ }^{125} \text {-labeled fibrin deposition) } \\
\text { in purified solutions (human) }\end{array}$ & $\begin{array}{l}\text { rMASP-2 cleaves prothrombin (presence of } \\
\text { pre-thrombin and fragment 1) and gener- } \\
\text { ates active thrombin, but at a lower rate } \\
\text { than FXa } \\
\text { MBL-MASP-2 complexes induce fibrin for- } \\
\text { mation on mannan-coated plates and } \\
\text { S. aureus-coated beads in the presence of } \\
\text { prothrombin }\end{array}$ \\
\hline $\begin{array}{l}\text { Hajela } \\
\text { et } \mathrm{al}^{54} \\
2002\end{array}$ & rMASP-1 & $\begin{array}{l}\text { Ability of MASP-1 to cleave fibrinogen } \\
\text { Purified fibrinogen/FXIII (human) }\end{array}$ & $\begin{array}{l}\text { MASP-1 cleaves fibrinogen and induces } \\
\text { crosslinking (generation of } \mathrm{Y}_{2} \text { - and } \\
\alpha_{n} \text {-chains) }\end{array}$ \\
\hline
\end{tabular}

Abbreviations: C, complement factor; F, coagulation factor; MAp44, MBL-associated protein of 44 kD; MASP, MBL-associated serine protease; MBL, mannose-binding lectin; $r$, recombinant. 


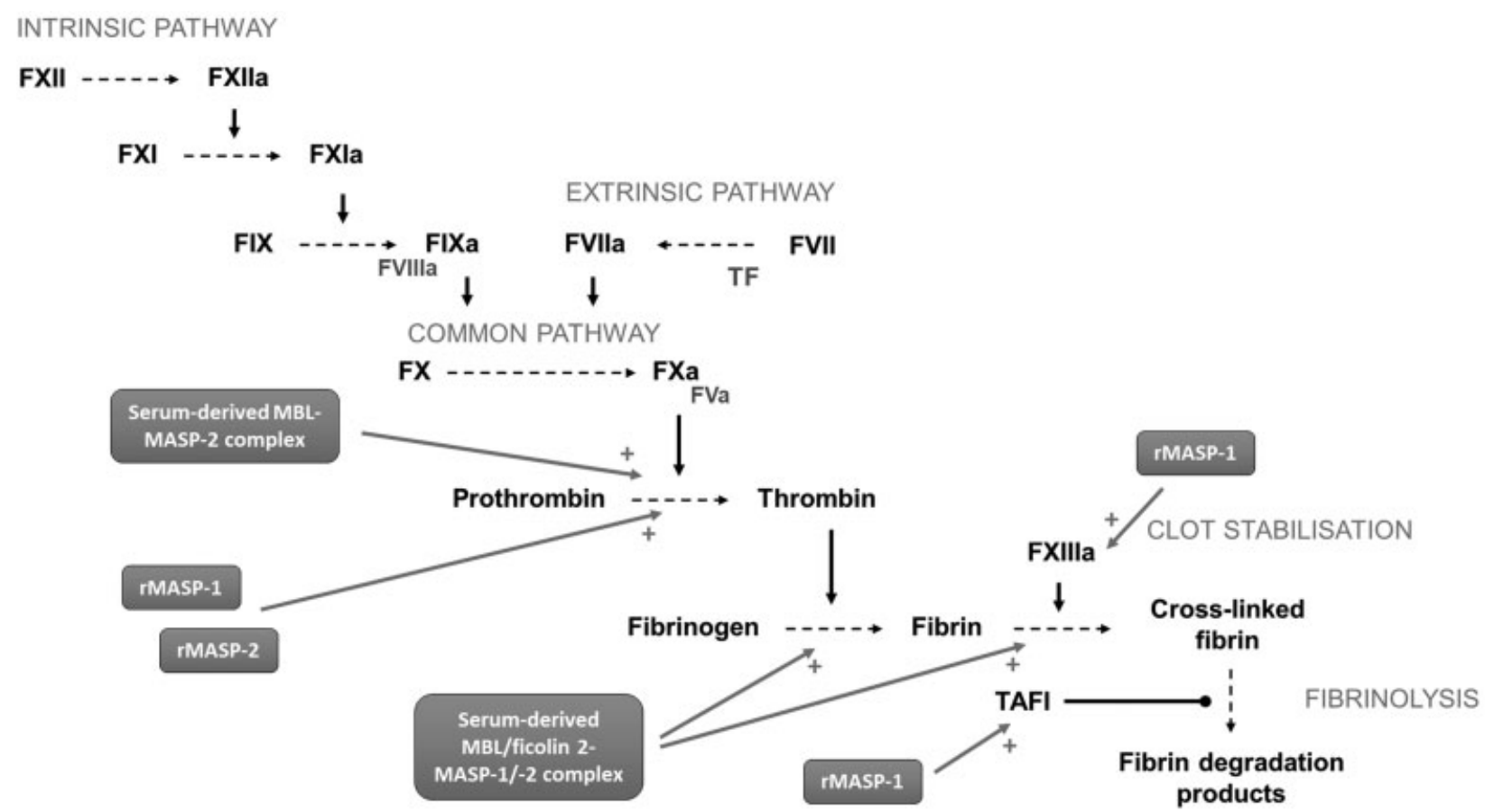

Fig. 2 Proteases of the lectin pathway induce thrombin and fibrin generation, stabilize the fibrin clot and impair fibrinolysis. The figure displays our current knowledge of the interactions between MASP- 1 and -2 and the coagulation and fibrinolytic system. ${ }^{52-62}$ Abbreviations: MASP, MBLassociated serine protease; MBL, mannose-binding lectin; rMASP, recombinant MASP; TF, tissue factor; TAFI, thrombin-activated fibrinolysis inhibitor. Roman numerals denote coagulation factors and the suffix 'a' denotes an activated factor. Black arrows denote enzymatic activity of coagulation factors on the next step in the cascade. Grey arrows with ' + ' denotes activation by lectin pathway proteases.

"mesenteric thrombosis") OR "hepatic thrombosis") OR “peripheral artery occlusion").

\section{Embase}

('Mannose binding lectin'/exp OR 'Complement lectin pathway'/exp OR 'Complement activation'/exp OR 'Mannan binding lectin associated serine proteinase'/exp OR 'Ficolin'/exp OR 'Map19' OR 'Map44' OR 'Collectin liver 1') AND ('Thromboembolism'/exp OR 'Heart muscle ischemia'/exp OR 'Heart infarction'/exp OR 'Brain ischemia'/exp OR 'Cerebrovascular accident'/exp OR 'Disseminated intravascular clotting'/exp OR 'Blood clotting').

Other relevant literature was identified by checking the reference lists of recent original studies and reviews and employing the 'cited-by' function in Scopus.

\section{Inclusion and Exclusion}

The inclusion criteria were: (1) original work, (2) human study population and ( 3 ) investigating associations between the lectin pathway and thromboembolic disease or laboratory coagulation parameters (surrogate endpoints for increased thrombosis risk). Both interventional and observational studies, including prospective cohort studies as well as case-control studies, were eligible for inclusion. Accepted endpoints for the lectin pathway were plasma or serum protein levels, genetic polymorphisms, gene expression and activation assays for one or more of the following proteins: MBL, ficolin-1, $-2,-3$, CL-L1 or -K1, MASP-1, -2 , -3 , MAp44 and MAp19. Accepted endpoints for thromboem- bolic disease were both microscopic thrombosis (e.g. disseminated intra-vascular coagulation) and large vessel occlusion, and both arterial and venous thrombosis. We included acute ischaemic stroke and cardiovascular thrombotic events (CVEs) defined as acute coronary syndrome (myocardial infarction [MI] and unstable angina pectoris) but not transient cerebral ischaemia, stable angina pectoris or atherosclerotic lesions without sign of thrombosis. Exclusion criteria were (1) case studies including fewer than five cases, (2) other language than English and (3) conference abstracts.

Fifty abstracts were randomly selected and screened for either exclusion or full-text reading by all three authors, and any disagreement was solved by consensus. The remaining abstracts were screened by J.B.L. In a similar fashion, 20 papers proceeding to full-text reading were randomly selected and read in full by all authors, and any disagreement was again solved by consensus. Inclusion or exclusion of the remaining papers were performed by J.B.L., and in case of doubt, all three authors discussed the study in question.

\section{Data Extraction and Quality Assessment}

Data extraction from the included articles was performed by J.B.L. and checked by C.L.H. and A.M.H. Study quality was assessed using the Quality Assessment Tool for Observational Cohort and Cross-Sectional Studies ${ }^{64}$ and the Quality Assessment Tool for Case-Control Studies, ${ }^{65}$ National Institutes of Health, USA. The quality assessment tools provide a guide for 
systematically assessing the risk of different types of bias in the study and thus the internal validity of the results. The tools comprise a list of items concerning key methodological points and specific criteria to be fulfilled for each item. A numeric rating scale is not employed; instead, each study is rated 'good', 'fair' or 'poor' according to the estimated risk of serious bias (low, intermediate or high), which is based on the number and types of criteria not fulfilled. Quality assessment was performed by all the three authors for all included studies, and disagreement was solved by consensus.

\section{Data Synthesis}

The included studies were heterogeneous regarding the design, study populations and endpoints, thus a complete meta-analysis of the data was not performed. Forest plots were made for the CVE sub-group to visualize results and support our qualitative data synthesis using Stata 14 (StataCorp, Texas, United States). If data for forest plots could not be extracted from the included article, an attempt to obtain data was made via emails to the corresponding authors.

\section{Results}

In total, 43 original articles were included in the present review and are presented in - Tables 3-6. The screening and inclusion/exclusion process is displayed in detail in - Fig. $\mathbf{3}$.

We grouped the studies first according to their major clinical focus and second according to their design. Among

Table 3 Studies investigating associations between the lectin pathway and occurrence of cardiovascular events

\begin{tabular}{|c|c|c|c|c|}
\hline Author, year, rating & $\begin{array}{l}\text { Design } \\
\text { Lectin pathway } \\
\text { parameters } \\
\text { Laboratory methods }\end{array}$ & Study population & $\begin{array}{l}\text { Endpoint(s) for } \\
\text { cardiovascular } \\
\text { events (CVE) }\end{array}$ & Results \\
\hline \multicolumn{5}{|c|}{ Prospective studies including nested case-control studies $(n=10)$} \\
\hline $\begin{array}{l}\text { Poppelaars et al } \\
2016 \\
\text { Rating: Good }\end{array}$ & $\begin{array}{l}\text { Longitudinal } \\
\text { Plasma MBL (EDTA), } \\
\text { ELISA }\end{array}$ & $\begin{array}{l}\text { Patients: end-stage } \\
\text { kidney disease on } \\
\text { haemodialysis } \\
(n=107) \\
\text { Mean follow-up: } 27 \\
\text { months } \\
\text { Censored if received } \\
\text { transplantation } \\
\text { Age: } 63 \pm 16 \text { years } \\
\text { Gender (M/F, \%): } 66 / 34\end{array}$ & $\begin{array}{l}\text { (1) Cardiac events (CE) } \\
\text { alone: MI, UAP, CABG } \\
\text { or PCI } \\
\text { (2) CVE: MI, UAP, } \\
\text { CABG, PCI, ischaemic } \\
\text { stroke or claudication } \\
\text { (3) All-cause mortality }\end{array}$ & $\begin{array}{l}\uparrow \mathrm{CE} \text { and } \uparrow \mathrm{CVE} \text { asso- } \\
\text { ciated with } \downarrow \mathrm{MBL} \\
\text { (adjusted } \mathrm{HR}=3.96 \\
{[1.49-10.54] \text { for } \mathrm{CE}} \\
\text { and } 3.98[1.88-8.42] \\
\text { for CVE) } \\
\text { Mortality not asso- } \\
\text { ciated with MBL (HR } \\
\text { not reported) } \\
\text { MBL improved predic- } \\
\text { tion of CVE } \\
\text { (Harrell's C }=0.76 \text { vs. } \\
0.73, p=0.01 \text { in a } \\
\text { model with vs. without } \\
\text { MBL) }\end{array}$ \\
\hline $\begin{array}{l}\text { Siezenga et al } \\
2011 \\
\text { Rating: Good }\end{array}$ & $\begin{array}{l}\text { Longitudinal } \\
\text { MBL2 genotype } \\
\text { Codon 52, 54, } 57 \\
\text { Serum MBL, ELISA }\end{array}$ & $\begin{array}{l}\text { Patients: type } 2 \text { dia- } \\
\text { betes }(n=134) \\
\text { Mean follow-up: } 7.7 \\
\text { years } \\
\text { Age: } 51 \pm 11 \text { years } \\
\text { Gender (M/F, \%): } 46 / 54 \\
\text { Ethnicity: South Asian }\end{array}$ & $\begin{array}{l}\text { MI, PCI, CABG or sud- } \\
\text { den cardiac death }\end{array}$ & $\begin{array}{l}\uparrow \text { CVE in low versus } \\
\text { intermediate/high } \\
\text { genotype } \\
(\mathrm{HR}=3.43[1.24- \\
9.49]) \\
\text { CVE not associated } \\
\text { with serum MBL (HR } \\
=0.93[0.50-1.73])\end{array}$ \\
\hline $\begin{array}{l}\text { Troelsen et } \mathrm{al}^{37} \\
2010 \\
\text { Rating: Fair }\end{array}$ & $\begin{array}{l}\text { Longitudinal } \\
\text { MBL2 genotype } \\
\text { Promoter }-221 \text {, codon } \\
52,54,57 \\
\text { Serum MBL, ELISA }\end{array}$ & $\begin{array}{l}\text { Patients: rheumatoid } \\
\text { arthritis }(n=229) \\
\text { Mean follow-up: } 10.3 \\
\text { years } \\
\text { Gender (M/F, \%): 18/82 }\end{array}$ & $\begin{array}{l}\text { (1) CVE-related mor- } \\
\text { tality } \\
\text { (2) All-cause mortality }\end{array}$ & $\begin{array}{l}\uparrow \text { CVE-related and } \\
\text { overall mortality asso- } \\
\text { ciated with high versus } \\
\text { intermediate/low gen- } \\
\text { otype (adjusted HR } \\
=2.0 \text { [1.0-4.1] for } \\
\text { CVE-related and } 1.7 \\
{[1.1-2.8] \text { for overall) }} \\
\uparrow \text { CVE and overall } \\
\text { mortality associated } \\
\text { with } \uparrow \text { serum MBL } \\
\text { (adjusted HR }=1.3 \\
{[1.0-1.5] \text { for CVE and }} \\
1.2[1.0-1.3] \text { for } \\
\text { overall) }\end{array}$ \\
\hline
\end{tabular}


Table 3 (Continued)

\begin{tabular}{|c|c|c|c|c|}
\hline Author, year, rating & $\begin{array}{l}\text { Design } \\
\text { Lectin pathway } \\
\text { parameters } \\
\text { Laboratory methods }\end{array}$ & Study population & $\begin{array}{l}\text { Endpoint(s) for } \\
\text { cardiovascular } \\
\text { events (CVE) }\end{array}$ & Results \\
\hline \multicolumn{5}{|c|}{ Prospective studies including nested case-control studies $(n=10)$} \\
\hline $\begin{array}{l}\text { Troelsen et al } \\
2007^{\mathrm{a}} \\
\text { Rating: Good }\end{array}$ & $\begin{array}{l}\text { Longitudinal } \\
\text { MBL2 genotype } \\
\text { Promoter }-221, \\
\text { codon 52, 54, } 57 \\
\text { Serum MBL, ELISA }\end{array}$ & $\begin{array}{l}\text { Patients: rheumatoid } \\
\text { arthritis }(n=229) \\
\text { Mean follow-up: } 9.5 \\
\text { years } \\
\text { Gender (M/F, \%): } 18 / 82\end{array}$ & $\begin{array}{l}\text { (1) MI } \\
\text { (2) CVE-related } \\
\text { mortality }\end{array}$ & $\begin{array}{l}\uparrow C V E \text { in high versus } \\
\text { intermediate/low } \\
\text { genotype } \\
\text { (adjusted } \mathrm{HR}=5.0 \\
{[1.4-17.5] \text { for } \mathrm{MI} \text { and }} \\
4.1[1.2-14.3] \text { for } \\
\text { mortality) } \\
\uparrow \mathrm{CVE} \text { associated with } \\
\uparrow \text { serum } \mathrm{MBL} \\
\text { (adjusted HR }=6.3 \\
{[2.0-20.1] \text { for } \mathrm{Ml} \text { and }} \\
10.5[2.7-41.3] \text { for } \\
\text { mortality }\end{array}$ \\
\hline $\begin{array}{l}\text { Berger et al }{ }^{69} \\
2007 \\
\text { Rating: Fair }\end{array}$ & $\begin{array}{l}\text { Longitudinal } \\
\text { MBL2 genotype } \\
\text { Codon 52, 54, } 57 \\
\text { Serum MBL, ELISA }\end{array}$ & $\begin{array}{l}\text { Patients: pancreas-kid- } \\
\text { ney transplant recipi- } \\
\text { ents } \\
\text { (genotype, } n=97 ; \\
\text { serum MBL, } n=99 \text { ) } \\
\text { Follow-up: } 12 \text { years } \\
\text { High/low MBL: } \\
\text { Age: } 40 \pm 8 / 41 \pm 7 \\
\text { years } \\
\text { Gender (M/F, \%): 68/32 } \\
\text { and } 61 / 39\end{array}$ & $\begin{array}{l}\text { (1) CVE-related mor- } \\
\text { tality } \\
\text { (2) Overall mortality }\end{array}$ & $\begin{array}{l}\uparrow \text { CVE mortality asso- } \\
\text { ciated with } \uparrow \text { serum } \\
\mathrm{MBL}(0 / 34 \text { deaths vs. } \\
11 / 65 \text { deaths, } \\
p=0.01) \\
\uparrow \text { overall mortality } \\
\text { associated with } \uparrow \\
\text { serum MBL } \\
\text { (adjusted HR }=4.4 \\
[1.30-15.10]) \\
\text { Mortality not asso- } \\
\text { ciated with genotype } \\
\text { in multivariate analysis } \\
\text { (HR not reported) }\end{array}$ \\
\hline $\begin{array}{l}\text { Keller et al } \\
2006 \\
\text { Rating: Good }\end{array}$ & $\begin{array}{l}\text { Nested case-control } \\
\text { Serum MBL, ELISA }\end{array}$ & $\begin{array}{l}\text { Patients: CVE during } \\
\text { follow-up }(n=781) \\
\text { Controls matched for } \\
\text { age, gender, date of } \\
\text { visit }( \pm 3 \text { months) } \\
\text { and duration of follow- } \\
\text { up }(n=1,505) \\
\text { Mean follow-up: } 6 \\
\text { years } \\
\text { Cases/controls: } \\
\text { Age: Men } 65 \pm 8 / \\
64 \pm 8, \text { years; women } \\
67 \pm 7 / 67 \pm 7 \text { years } \\
\text { Gender (M/F, \%): } \\
62 / 38 \text { and } 64 / 36\end{array}$ & $\begin{array}{l}\text { MI or CVE-related } \\
\text { mortality }\end{array}$ & $\begin{array}{l}\text { In men: } \uparrow \text { CVE asso- } \\
\text { ciated with } \uparrow \mathrm{MBL} \\
\text { (adjusted OR }=1.55 \\
{[1.08-2.22] \text { in highest }} \\
\text { vs. lowest MBL quar- } \\
\text { tile) } \\
\text { In women: no associa- } \\
\text { tion between MBL and } \\
\text { CVE (adjusted OR } \\
=0.98[0.61-1.56] \text { ) }\end{array}$ \\
\hline $\begin{array}{l}\text { Saevarsdottir et al } \\
2005 \\
\text { Rating: Good }\end{array}$ & $\begin{array}{l}\text { Nested case-control } \\
\text { Serum MBL, ELISA }\end{array}$ & $\begin{array}{l}\text { Patients: CVE during } \\
\text { follow-up }(n=867) \\
\text { Controls }(n=442) \text {, } \\
\text { matching not reported } \\
\text { Mean follow-up: } 27 \\
\text { years } \\
\text { Cases/controls: } \\
\text { Age: } 56(51-62) \text { years } \\
\text { /55 }(50-61) \text { years } \\
\text { Gender }(M / F, \%): 58 / 42 \\
\text { and } 50 / 50\end{array}$ & $\begin{array}{l}\text { MI or CVE-related } \\
\text { mortality }\end{array}$ & $\begin{array}{l}\text { Overall: No association } \\
\text { between CVE and } \mathrm{MBL} \\
\text { (OR }=0.88[0.69-1.1] \\
\downarrow \mathrm{CVE} \text { associated with } \\
\uparrow \mathrm{MBL} \text { in patients with } \\
\text { diabetes }(\mathrm{OR}=0.15 \\
[0.03-0.78]) \text { and } \\
\text { hypercholesterolae- } \\
\text { mia }(\mathrm{OR}=0.26 \\
[0.10-0.64])\end{array}$ \\
\hline $\begin{array}{l}\text { Hertle et al }{ }^{45} \\
2016 \\
\text { Rating: Fair }\end{array}$ & $\begin{array}{l}\text { Longitudinal } \\
\text { MBL2 genotype } \\
\text { Codon 52, } 57 \\
\text { Plasma MBL (EDTA), }\end{array}$ & $\begin{array}{l}\text { Healthy or diabetic } \\
\text { subjects }(n=495) \text {; } \\
\text { Type } 2 \text { diabetes or } \\
\text { impaired glucose }\end{array}$ & $\begin{array}{l}\text { MI, ischaemic stroke, } \\
\text { CABG or PCI during } \\
\text { follow-up }\end{array}$ & $\begin{array}{l}\text { No associations } \\
\text { between LP and CVE } \\
\text { MBL2 genotype: OR } \\
=1.60[0.73-3.51])\end{array}$ \\
\hline
\end{tabular}


Table 3 (Continued)

\begin{tabular}{|c|c|c|c|c|}
\hline Author, year, rating & $\begin{array}{l}\text { Design } \\
\text { Lectin pathway } \\
\text { parameters } \\
\text { Laboratory methods }\end{array}$ & Study population & $\begin{array}{l}\text { Endpoint(s) for } \\
\text { cardiovascular } \\
\text { events (CVE) }\end{array}$ & Results \\
\hline \multicolumn{5}{|c|}{ Prospective studies including nested case-control studies $(n=10)$} \\
\hline & $\begin{array}{l}\text { MASP-1, }-2,-3, \text { MAp44 } \\
\text { (citrate), ELISA }\end{array}$ & $\begin{array}{l}\text { tolerance: } 48 \% \\
\text { Follow-up: } 7 \text { years } \\
\text { Age: } 60 \pm 7 \text { years } \\
\text { Gender }(\mathrm{M} / \mathrm{F}, \%): 61 / 39\end{array}$ & & $\begin{array}{l}\text { MASPs, MAp44: ORs } \\
\text { not reported }\end{array}$ \\
\hline $\begin{array}{l}\text { Vengen et } \mathrm{al}^{72} \\
2012 \\
\text { Rating: Good }\end{array}$ & $\begin{array}{l}\text { Nested case-control } \\
\text { MBL2 genotype } \\
\text { Promoter -221, codon } \\
52,54,57 \\
\text { FCN1 promoter }-542 \\
\text { SNP; FCN2 exon } 8 \\
\text { +6359 and +6424; } \\
\text { FCN3 + } 1637 \text { SNP }\end{array}$ & $\begin{array}{l}\text { Patients: MI during } \\
\text { follow-up }(n=370) \\
\text { Controls matched for } \\
\text { age and gender } \\
(n=370) \\
\text { Mean follow-up: } 12 \\
\text { years } \\
\text { Cases: } \\
\text { Age: } 48 \text { (range: } 29- \\
\text { 62) years } \\
\text { Gender (M/F, \%): } 76 / 24\end{array}$ & MI & $\begin{array}{l}\uparrow \mathrm{MI} \text { in low versus } \\
\text { intermediate/high } \\
M B L 2 \text { genotype } \\
\text { (adjusted OR }=2.02 \\
{[1.17-3.47] \text { ) }} \\
\text { No association } \\
\text { between FCN poly- } \\
\text { morphisms and MI (all } \\
p>0.19, \text { OR not } \\
\text { reported) }\end{array}$ \\
\hline $\begin{array}{l}\text { Vengen et } \mathrm{al}^{73} \\
2017^{\mathrm{b}} \\
\text { Rating: Good }\end{array}$ & $\begin{array}{l}\text { Nested case-control } \\
\text { Serum ficolin-1, -2, -3, } \\
\text { MASP-3, MAp44, ELISA }\end{array}$ & $\begin{array}{l}\text { Patients: MI during } \\
\text { follow-up }(n=370) \\
\text { Controls matched for } \\
\text { age and gender } \\
(n=370) \\
\text { Mean follow-up: } 12 \\
\text { years } \\
\text { Cases: } \\
\text { Age: } 48 \text { (range: } 29- \\
\text { 62) years } \\
\text { Gender (M/F, \%): 76/24 }\end{array}$ & $\mathrm{MI}$ & $\begin{array}{l}\uparrow \mathrm{MI} \text { in highest tertile } \\
\text { of ficolin-2 (adjusted } \\
\mathrm{OR}=1.55[1.04-2.30]) \\
\downarrow \mathrm{MI} \text { in highest tertile of } \\
\text { MASP-3 (adjusted OR } \\
=0.63 \text { [0.04-0.94]) } \\
\text { No association with MI } \\
\text { for ficolin-1 (OR }=0.77 \\
[0.52-1.13]), \text { ficolin-3 } \\
(\mathrm{OR}=1.17[0.79- \\
1.73]) \text { or MAp44 (OR } \\
=0.86[0.59-1.27])\end{array}$ \\
\hline \multicolumn{5}{|c|}{ Cross-sectional and case-control studies $(n=4)$} \\
\hline $\begin{array}{l}\text { Pesonen et } \text { al }^{74} \\
2009 \\
\text { Rating: Fair }\end{array}$ & $\begin{array}{l}\text { Case-control } \\
\text { MBL2 genotype } \\
\text { Promoter }-550 \text { and } \\
221, \text { codon 52, 54, } 57 \\
\text { Serum MBL, ELISA }\end{array}$ & $\begin{array}{l}\text { Patients: UAP } \\
(n=113) \text { or } \mathrm{MI} \\
(n=241) \\
\text { Controls: healthy } \\
\text { volunteers matched } \\
\text { for age, gender and } \\
\text { parish }(n=334) \\
\text { Cases: } \\
\text { Age: } 63 \text { years } \\
\text { Gender (M/F, \%): 78/22 }\end{array}$ & $\begin{array}{l}\text { (1) UAP } \\
\text { (2) MI }\end{array}$ & $\begin{array}{l}\uparrow \text { serum } \mathrm{MBL} \text { and high } \\
\text { genotype associated } \\
\text { with } \uparrow \text { UAP (adjusted } \\
\mathrm{OR}=1.25 \\
{[p=0.006] \text { for serum }} \\
\mathrm{MBL} \text { and } 1.16 \\
{[p=0.01] \text { for geno- }} \\
\text { type) and with } \uparrow \mathrm{MI} \\
\text { (adjusted } \mathrm{OR}=1.28 \\
{[p<0.001] \text { for serum }} \\
\mathrm{MBL} \text { and } 1.12 \\
{[p=0.007] \text { for }} \\
\text { genotype) }\end{array}$ \\
\hline $\begin{array}{l}\text { Hansen et } \mathrm{al}^{75} \\
2004 \\
\text { Rating: Fair }\end{array}$ & $\begin{array}{l}\text { Case-control } \\
\text { MBL2 genotype } \\
\text { Promoter }-550 \text { and } \\
221, \text { UTR }+4 \text {, codon } \\
52,54,57 \\
\text { Serum MBL, TRIFMA }\end{array}$ & $\begin{array}{l}\text { Patients: type } 1 \text { dia- } \\
\text { betes and nephropa- } \\
\text { thy }(n=199) \\
\text { or normoalbuminuria } \\
(n=192) \text { matched for } \\
\text { age, gender and dura- } \\
\text { tion of diabetes } \\
\text { Controls: healthy } \\
\text { volunteers matched } \\
\text { for age }(n=100) \\
\text { Cases: } \\
\text { Age: } 41 \pm 10 \text { years } \\
\text { Gender (M/F, \%): } 61 / 39 \\
\text { Ethnicity: Caucasian }\end{array}$ & $\begin{array}{l}\text { MI, stroke or } \\
\text { claudication }\end{array}$ & $\begin{array}{l}\uparrow \text { serum MBL in } \\
\text { patients with previous } \\
\text { CVE (mean difference } \\
880 \mu \mathrm{g} / \mathrm{L}, p=0.02) \\
\text { This difference per- } \\
\text { sisted in patients with } \\
\text { high genotype } \\
(p<0.001) \text { but not } \\
\text { low genotype } \\
(p=0.31)\end{array}$ \\
\hline
\end{tabular}


Table 3 (Continued)

\begin{tabular}{|c|c|c|c|c|}
\hline Author, year, rating & $\begin{array}{l}\text { Design } \\
\text { Lectin pathway } \\
\text { parameters } \\
\text { Laboratory methods }\end{array}$ & Study population & $\begin{array}{l}\text { Endpoint(s) for } \\
\text { cardiovascular } \\
\text { events (CVE) }\end{array}$ & Results \\
\hline \multicolumn{5}{|c|}{ Cross-sectional and case-control studies $(n=4)$} \\
\hline $\begin{array}{l}\text { Frauenknecht et al } \\
2013 \\
\text { Rating: Fair }\end{array}$ & $\begin{array}{l}\text { Case-control } \\
\text { Plasma MASP-1, -2, -3 } \\
\text { or MAp44 (citrate), } \\
\text { TRIFMA }\end{array}$ & $\begin{array}{l}\text { Patients: MI }(n=49) \\
\text { Controls: healthy } \\
\text { volunteers }(n=50) \\
\text { and patients with } \\
\text { stable CAD }(n=104) \\
\text { Patients: } \\
\text { Age: } 57 \pm 9 \text { years } \\
\text { Gender (M/F, \%): } 80 / 20\end{array}$ & $\mathrm{Ml}$ & $\begin{array}{l}\uparrow \text { MASP- } 1 \text { and } \downarrow \text { MASP- } \\
2 \text { in MI compared with } \\
\text { controls (MASP- } 1: \\
11.93 \text { vs. } 9.44 \mu \mathrm{g} / \mathrm{mL} \text {, } \\
p<0.001 ; \text { MASP-2: } \\
369.8 \text { vs. } 442.9 \mathrm{ng} / \mathrm{mL} \text {, } \\
p=0.005) \\
\leftrightarrow \text { MASP-3 or MAp44 } \\
\text { between groups } \\
(p>0.05)\end{array}$ \\
\hline $\begin{array}{l}\text { Zhang et al } \\
2013 \\
\text { Rating: Fair }\end{array}$ & $\begin{array}{l}\text { Case-control } \\
\text { Plasma MASP-2 (anti- } \\
\text { coagulant not } \\
\text { reported), ELISA }\end{array}$ & $\begin{array}{l}\text { Patients: MI }(n=29) \\
\text { Controls: healthy } \\
\text { volunteers }(n=50) \text {; } \\
\text { patients with stable } \\
\text { CAD }(n=27) \\
\text { Patients: } \\
\text { Age: } 61(32-72) \text { years } \\
\text { Gender (M/F,\%): 69/31 } \\
\text { Ethnicity: } \\
\text { African American 59\%, } \\
\text { Caucasian } 10 \% \text {, Hispa- } \\
\text { nic } 31 \%\end{array}$ & $\mathrm{MI}$ & $\begin{array}{l}\downarrow \text { MASP-2 in MI versus } \\
\text { healthy or CAD con- } \\
\text { trols ( } 235 \text { vs. } 460 \\
\text { [healthy] and } 471 \mathrm{ng} / \\
\text { mL [CAD], } p<0.01 \text { ) }\end{array}$ \\
\hline
\end{tabular}

Abbreviations: CABG, coronary artery bypass grafting; CAD, coronary artery disease; CPB, cardiopulmonary bypass; CVE, cardiovascular event; EDTA, ethylenediaminetetraacetic acid; ELISA, enzyme-linked immunosorbent assay; FCN, gene encoding ficolin; HR, hazard ratio; LP, lectin pathway; MAp44, MBL-associated protein of 44 kDa (also known as MAP1); MASP, MBL-associated protease; MBL, mannose-binding lectin; MBL2, gene encoding MBL; MI, myocardial infarction; OR, odds ratio; $\mathrm{PCl}$, percutaneous coronary intervention; SNP, single-nucleotide polymorphism; STEMI, ST-segment elevation myocardial infarction; TRIFMA, time-resolved immunofluorometric assay; UAP, unstable angina pectoris. Notes: Study population: Age, gender and ethnicity are stated if reported in the study. Age is rounded to whole years and indicated by mean \pm standard deviation or median (interquartiles) unless otherwise specified. Results: Numbers in parentheses after OR/HR are $95 \%$ confidence intervals unless otherwise specified.

a Same study population as Troelsen et al $2010 .^{37}$

bame study population as Vengen et al 2012. ${ }^{72}$

the included studies, 22 focused on CVE, predominantly $\mathrm{MI},{ }^{37,45,66-85} 9$ on ischaemic stroke, ${ }^{86-94} 1$ on both CVE and stroke $^{95}$ and 11 on other conditions (SLE, $n=6,{ }^{41,61,96-99}$ disseminated intravascular coagulation [DIC], $n=3,^{102,103,105}$ pulmonary embolism, $n=1^{100}$ and L-asparaginase-treated pediatric patients, $n=1^{101}$ ).

Out of 23 CVE studies, 16 investigated associations between the lectin pathway and occurrence of CVE, 37,45,66-76,83,84,95 while 9 of the 23 prospectively investigated associations between the lectin pathway and outcome (e.g. mortality or recurrent MI) in patients with existing CVE. ${ }^{77-85}$ Among the 10 studies on ischaemic stroke, 8 investigated associations between lectin pathway proteins and occurrence of stroke (case-control design), ${ }^{86-92,95}$ and 6 of the 10 studies investigated associations between lectin pathway proteins and stroke severity and/or functional outcome in existing stroke (prospective or cross-sectional design). ${ }^{88-90,92-94}$

The majority of studies $(n=33)$ included MBL serum/ plasma levels and/or MBL2 genotype, while nine studies investigated one or more MASPs, ${ }^{45,61,73,76,84,85,94,95,100}$ seven studies one or more ficolins, ${ }^{41,72,73,83,86,88,92}$ five studies MAp44 $45,73,83,84,95$ and one investigated CL-K1. ${ }^{102}$ Studies including MBL2 genotype all investigated polymorphisms in codon 52, 54 and 57 in exon $1 .^{37,45,67-69,72,74,75,77,80,94,96-99,103}$ Additionally, some included one or more of three polymorphisms in the promoter or $5^{\prime}$ untranslated region $37,68,72,74,75,77,80,94,97,99$ (please refer to -Table $\mathbf{1}$ ). All studies classified the patients' genotypes or haplotypes after their known association with MBL expression and serum levels. Thus, genotype was classified overall as 'high' (wild-type), 'intermediate' or 'low' in these studies, and this classification is used throughout the text and tables of the present review.

The overall study quality was moderate to high, with 22 (51\%) rating 'good', 17 (40\%) rating 'fair' and 4 (9\%) rating 'poor'. The individual ratings are provided in - Tables 3-6.

Below, we summarize the findings of the included studies on associations between the lectin pathway and thrombotic events. 
Table 4 Studies investigating associations between the lectin pathway and disease severity or outcome in existing cardiovascular disease

\begin{tabular}{|c|c|c|c|c|}
\hline Author, year, rating & $\begin{array}{l}\text { Design } \\
\text { Lectin pathway para- } \\
\text { meters }\end{array}$ & Study population & $\begin{array}{l}\text { Endpoints for disease } \\
\text { severity or outcome }\end{array}$ & Results \\
\hline $\begin{array}{l}\text { Mellbin et al } \\
2010 \\
\text { Rating: Good }\end{array}$ & $\begin{array}{l}\text { Longitudinal, baseline } \\
\text { blood sampling shortly } \\
\text { after MI diagnosis } \\
\text { MBL2 genotype } \\
\text { Promoter -221, codon } \\
52,54,57 \\
\text { Serum MBL, TRIFMA }\end{array}$ & $\begin{array}{l}\text { Patients: type } 2 \text { dia- } \\
\text { betes and MI }(n=387 \\
\text { serum only and } \\
n=287 \text { serum and } \\
\text { genotype) } \\
\text { Mean follow-up: } 2.5 \\
\text { years } \\
\text { Age: } 70(61-77) \text { years } \\
\text { Gender (M/F, \%): 68/32 }\end{array}$ & $\begin{array}{l}\text { Recurrent MI, ischae- } \\
\text { mic stroke or CVE- } \\
\text { related mortality }\end{array}$ & $\begin{array}{l}\text { No association } \\
\text { between CVE and } \\
\text { serum MBL or geno- } \\
\text { type }(\mathrm{HR}=0.93 \\
[0.85-1.01])\end{array}$ \\
\hline $\begin{array}{l}\text { Trendelenburg et al } \\
2010 \\
\text { Rating: Good }\end{array}$ & $\begin{array}{l}\text { Longitudinal, baseline } \\
\text { blood sampling before } \\
\text { PCI } \\
\text { Serum MBL, ELISA }\end{array}$ & $\begin{array}{l}\text { Patients: STEMI, } \\
\text { undergoing primary } \\
\text { PCI }(n=890) \\
\text { Follow-up: } 90 \text { days } \\
\text { Low/high MBL } \\
\text { Age: } 60(53-73) \text { years } \\
\text { /60 (51-70) years } \\
\text { Gender (M/F, \%): } 76 / 42 \\
\text { and } 79 / 21\end{array}$ & $\begin{array}{l}\text { (1) All-cause mortality } \\
\text { (2) Cardiac dysfunc- } \\
\text { tion: Composite end- } \\
\text { point of death, } \\
\text { cardiogenic shock or } \\
\text { heart failure }\end{array}$ & $\begin{array}{l}\downarrow \text { MBL associated with } \\
\downarrow \text { all-cause mortality } \\
\text { (HR }=0.14[0.02- \\
1.02], p=0.02) \text { but } \\
\text { not with cardiac dys- } \\
\text { function }(\mathrm{HR}=0.89 \\
[0.52-1.53])\end{array}$ \\
\hline $\begin{array}{l}\text { Haahr-Pedersen et al } \\
2009 \\
\text { Rating: Good }\end{array}$ & $\begin{array}{l}\text { Longitudinal, baseline } \\
\text { blood sampling before } \\
\text { PCI } \\
\text { Plasma MBL (EDTA), } \\
\text { TRIFMA }\end{array}$ & $\begin{array}{l}\text { Patients: STEMI, } \\
\text { undergoing primary } \\
\text { PCI }(n=74) \\
\text { Follow-up: } 48 \text { hours } \\
\text { Ejection fraction } \\
>35 \% /<35 \% \\
\text { Age: } 62 \text { years }{ }^{58-65} / 63 \\
\text { (59-68) years } \\
\text { Gender (M/F, \%): } 79 / 21 \\
\text { and } 81 / 19\end{array}$ & $\begin{array}{l}\text { Cardiac dysfunction: } \\
\text { left ventricle ejection } \\
\text { fraction }<35 \%\end{array}$ & $\begin{array}{l}\text { Cardiac dysfunction } \\
\text { associated with } \uparrow \mathrm{MBL} \\
\text { (adjusted OR }=5.5 \\
{[1.5-19.3] \text { ) }}\end{array}$ \\
\hline $\begin{array}{l}\text { Collard et al } \\
2007 \\
\text { Rating: Good }\end{array}$ & $\begin{array}{l}\text { Longitudinal } \\
\text { MBL2 genotype } \\
\text { Promoter }-550 \text { and } \\
221 \text {, UTR }+4 \text {, codon } \\
52,54,57\end{array}$ & $\begin{array}{l}\text { Patients undergoing } \\
\text { first-time isolated } \\
\text { CABG }(n=843) \\
\text { Follow-up: } 3 \text { days post- } \\
\text { operation } \\
\text { MI/no MI } \\
\text { Age: } 64 \pm 11 \text { years } \\
/ 65 \pm 10 \text { years } \\
\text { Gender (M/F, \%): } \\
74 / 26 \text { and } 79 / 21 \\
\text { Ethnicity: Caucasian }\end{array}$ & Post-operative MI & $\begin{array}{l}\text { The combination of a } \\
5^{\prime} \text { and a } 3^{\prime} \text { haplotype } \\
\text { encoding } \uparrow \text { serum } \\
\text { MBL was associated } \\
\text { with } \uparrow \mathrm{Ml} \\
\text { (adjusted OR }=4.72 \\
\text { [1.41-15.85]) } \\
\text { No association found } \\
\text { between any haplo- } \\
\text { type alone and MI (ORs } \\
\text { not reported) }\end{array}$ \\
\hline $\begin{array}{l}\text { Ueland et } \text { al }^{81} \\
2006 \\
\text { Rating: Fair }\end{array}$ & $\begin{array}{l}\text { Longitudinal, blood } \\
\text { sampling at study } \\
\text { enrolment and after } 1 \\
\text { month } \\
\text { Plasma MBL (EDTA), } \\
\text { EIA }\end{array}$ & $\begin{array}{l}\text { Patients: MI and } \downarrow \text { left } \\
\text { ventricle ejection frac- } \\
\text { tion }(n=234) \\
\text { Mean follow-up: } 2.7 \\
\text { years } \\
\text { Low/high MBL: } \\
\text { Age: } 68 \pm 10 \text { years } \\
/ 67 \pm 10 \text { years } \\
\text { Gender }(\mathrm{M} / \mathrm{F}, \%) \text { : } \\
63 / 37 \text { and } 74 / 26\end{array}$ & $\begin{array}{l}\text { (1) Recurrent MI } \\
\text { (2) Overall mortality }\end{array}$ & $\begin{array}{l}\uparrow \text { recurrent } \mathrm{Ml} \text { at } 1 \mathrm{mo} \\
\text { associated with } \downarrow \mathrm{MBL} \\
\text { (adjusted } \mathrm{HR}=2.3 \\
{[1.2-4.5] \text { to } 2.7 \text { [1.4- }} \\
5.2] \text { depending on the } \\
\text { model used) } \\
\text { No association } \\
\text { between MBL and } \\
\text { overall mortality (OR } \\
\text { not reported) }\end{array}$ \\
\hline $\begin{array}{l}\text { Limnell et } \mathrm{al}^{82} \\
2002 \\
\text { Rating: Poor }\end{array}$ & $\begin{array}{l}\text { Retrospective, blood } \\
\text { sampling at the end of } \\
\text { follow-up } \\
\text { Serum MBL, EIA }\end{array}$ & $\begin{array}{l}\text { Patients undergoing } \\
\text { CABG with one or } \\
\text { more venous graft } \\
(n=62) \\
\text { Median follow-up: } 1.3 \\
\text { years } \\
\text { Age: } 56 \text { ( } 43-67) \text { years } \\
\text { Gender: all male }\end{array}$ & Graft occlusion & $\begin{array}{l}\uparrow \text { graft occlusion asso- } \\
\text { ciated with } \downarrow \mathrm{MBL} \\
\text { (adjusted OR }=11.5 \\
{[1.24-106] \text { ) }}\end{array}$ \\
\hline
\end{tabular}


Table 4 (Continued)

\begin{tabular}{|c|c|c|c|c|}
\hline Author, year, rating & $\begin{array}{l}\text { Design } \\
\text { Lectin pathway para- } \\
\text { meters }\end{array}$ & Study population & $\begin{array}{l}\text { Endpoints for disease } \\
\text { severity or outcome }\end{array}$ & Results \\
\hline $\begin{array}{l}\text { Schoos et al } \\
2013 \\
\text { Rating: Fair }\end{array}$ & $\begin{array}{l}\text { (1) Case-control: } \\
\text { MI occurrence } \\
\text { (2) Longitudinal: } \\
\text { Cardiac function after } \\
\text { MI } \\
\text { Blood sampling at day } \\
\text { 1, 4, } 7 \text { and } 31 \text { after MI } \\
\text { Plasma MBL, ficolin-2, } \\
-3 \text { or MAp44 (EDTA), } \\
\text { ELISA }\end{array}$ & $\begin{array}{l}\text { Patients: MI under- } \\
\text { going primary PCI } \\
(n=55) \\
\text { Controls: reference } \\
\text { intervals in healthy } \\
\text { individuals } \\
\text { Follow-up: } 6 \text { months } \\
\text { Low/high ficolin-2: } \\
\text { Age: } 59(51-63) \text { years } \\
\text { /54 (50-62) years } \\
\text { Gender }(\mathrm{M} / \mathrm{F}, \%): \\
76 / 24 \text { and } 82 / 18\end{array}$ & $\begin{array}{l}\text { (1) MI } \\
\text { (2) Cardiac function: } \\
\text { Infarct size, end-dia- } \\
\text { stolic volume/body } \\
\text { surface area, end-sys- } \\
\text { tolic volume/body sur- } \\
\text { face area) and left } \\
\text { ventricle ejection } \\
\text { fraction }\end{array}$ & $\begin{array}{l}\downarrow \text { ficolin- } 2 \text { in MI } \\
\text { patients versus con- } \\
\text { trols (day } 1: 870 \text { vs. } \\
3,370 \text { ng/mL, } p \text { not } \\
\text { reported) } \\
\leftrightarrow \text { in MBL, ficolin-3 or } \\
\text { MAp44 in Ml versus } \\
\text { controls, } p \text { not } \\
\text { reported } \\
\uparrow \text { ficolin- } 2 \text { alone asso- } \\
\text { ciated with } \uparrow \text { end-dia- } \\
\text { stolic volume and } \uparrow \\
\text { end-systolic volume at } \\
\text { baseline but not } 6 \text { mo } \\
(p=0.004 \text { and } \\
<0.001) \\
\text { A combination of } \uparrow \\
\text { ficolin- } 2 \text { AND } \uparrow \text { MBL or } \\
\downarrow M A p 44 \text { was asso- } \\
\text { ciated with } \uparrow \text { EDV and } \\
\text { ESV from baseline to } 6 \\
\text { mo ( } p=0.006 \text { and } \\
p=0.025 \text { ) }\end{array}$ \\
\hline $\begin{array}{l}\text { Holt et al } \\
2014 \\
\text { Rating: Fair }\end{array}$ & $\begin{array}{l}\text { (1) Case-control: } \\
\text { MI occurrence } \\
\text { (2) Longitudinal: } \\
\text { Salvaged myocardium } \\
\text { Blood sample before } \\
\text { PCI } \\
\text { Plasma MASP-1, -3 or } \\
\text { MAp44 (EDTA), } \\
\text { TRIFMA }\end{array}$ & $\begin{array}{l}\text { Patients: MI }(n=122) \\
\text { undergoing PCl } \\
\text { Controls: Healthy } \\
\text { blood donors } \\
(n=140) \\
\text { Follow-up: } 30 \text { days } \\
\text { Age: } 63(56-72) \text { years } \\
\text { Gender (M/F, \%): } 77 / 23\end{array}$ & $\begin{array}{l}\text { Salvage index calcu- } \\
\text { lated from myocardial } \\
\text { area at risk estimated } \\
\text { before } \mathrm{PCl} \text { and final } \\
\text { infarct size }\end{array}$ & $\begin{array}{l}(1) \uparrow \text { MASP-1, MASP-3 } \\
\text { and MAp44 in MI } \\
\text { compared with con- } \\
\text { trols ( } p:<0.001- \\
0.002) \\
\text { (2) No correlation } \\
\text { between LP proteins } \\
\text { and salvage index or } \\
\text { area at risk (Spear- } \\
\text { man's r: }-0.12 \text { to } 0.02 \text {, } \\
\text { all } p>0.12 \text { ) }\end{array}$ \\
\hline $\begin{array}{l}\text { Mellbin et al } \\
2012^{a} \\
\text { Rating: Good }\end{array}$ & $\begin{array}{l}\text { Longitudinal, blood } \\
\text { sample at study enrol- } \\
\text { ment and } 3 \text { months } \\
\text { Plasma MASP-2 (antic- } \\
\text { oagulant not } \\
\text { reported), TRIFMA }\end{array}$ & $\begin{array}{l}\text { Patients: type } 2 \\
\text { diabetes and } \mathrm{Ml} \\
\text { ( } n=397) \\
\text { Mean follow-up: } 2.4 \\
\text { years } \\
\text { Age: } 70(61-77) \text { years } \\
\text { Gender (M/F, \%): 68/32 }\end{array}$ & $\begin{array}{l}\text { CVE: recurrent MI, } \\
\text { ischaemic stroke or } \\
\text { CVE-related death }\end{array}$ & $\begin{array}{l}\text { No association } \\
\text { between MASP-2 at } \\
\text { admission or } 3 \text { mo and } \\
\text { CVE }(H R=0.86 \\
[0.62-1.20])\end{array}$ \\
\hline
\end{tabular}

Abbreviations: $C A B G$, coronary artery bypass grafting; CAD, coronary artery disease; CPB, cardiopulmonary bypass; CVE, cardiovascular event; EDTA, ethylenediaminetetraacetic acid; EIA, enzyme immunoassay; ELISA, enzyme-linked immunosorbent assay; FCN, gene encoding ficolin; HR, hazard ratio; LP, lectin pathway; MAp44, MBL-associated protein of 44 kDa (also known as MAP1); MASP, MBL-associated protease; MBL, mannosebinding lectin; MBL2, gene encoding MBL; MI, myocardial infarction; OR, odds ratio; PCI, percutaneous coronary intervention; PTCA, percutaneous transluminal coronary angioplasty; STEMI, ST-segment elevation myocardial infarction; TRIFMA, time-resolved immunofluorometric assay; UAP, unstable angina pectoris.

Note: Study population: Age, gender and ethnicity are stated if reported in the study. Age is rounded to whole years and indicated by mean \pm standard deviation or median (interquartiles) unless otherwise specified. Results: Numbers in parentheses after OR/HR are $95 \%$ confidence intervals unless otherwise specified.

asame study population as Mellbin et al $2010 .{ }^{77}$

\section{Cardiovascular Events}

\section{The Lectin Pathway and Occurrence of Cardiovascular Events}

Studies investigating the lectin pathway and CVE occurrence are presented in $\mathbf{- T a b l e ~} \mathbf{3}$. The following endpoints for CVE were investigated: $\mathrm{MI}^{72-74,76,95}$ unstable angina pectoris, ${ }^{74}$
CVE-related mortality, ${ }^{37,69}$ all-cause mortality, ${ }^{37,66}$ myocardial revascularization procedure (coronary artery bypass grafting [CABG] or percutaneous coronary intervention $[\mathrm{PCI}])$, or a composite endpoint consisting of two or more of these. ${ }^{45,66-68,70,71,75}$ Some studies investigated the association between the lectin pathway and CVE in patients with other clinical conditions such as diabetes mellitus, ${ }^{45,67,71,75}$ 
Table 5 The lectin pathway in ischaemic stroke

\begin{tabular}{|c|c|c|c|c|}
\hline Author, year, rating & $\begin{array}{l}\text { Design } \\
\text { Lectin pathway para- } \\
\text { meters }\end{array}$ & Study population & $\begin{array}{l}\text { Endpoints for stroke } \\
\text { severity or outcome }\end{array}$ & Results \\
\hline $\begin{array}{l}\text { Kouchaki et al } \\
2017 \\
\text { Rating: Good }\end{array}$ & $\begin{array}{l}\text { Cross-sectional, blood } \\
\text { sampling at admission } \\
\text { Serum ficolin-1, ELISA }\end{array}$ & $\begin{array}{l}\text { Patients }(n=82) \\
\text { Age: } 70 \pm 14 \text { years } \\
\text { Gender }(M / F, \%): 51 / 49\end{array}$ & NIHSS at admission & $\begin{array}{l}\uparrow \text { ficolin- } 1 \text { correlated } \\
\text { moderately with } \uparrow \\
\text { NIHSS (multivariate } \\
\text { analysis, } \beta=0.73 \text {, } \\
p<0.001 \text { ) }\end{array}$ \\
\hline $\begin{array}{l}\text { Huang et } \text { al }^{87} \\
2016 \\
\text { Rating: Good }\end{array}$ & $\begin{array}{l}\text { Case-control, blood } \\
\text { sampling on the } \\
\text { morning after admis- } \\
\text { sion } \\
\text { Serum MBL, TRIFMA }\end{array}$ & $\begin{array}{l}\text { Patients }(n=175) \\
\text { Controls: healthy } \\
\text { volunteers matched } \\
\text { for age and gender } \\
(n=175) \\
\text { Age: } 68(57-75) \text { years } \\
\text { Gender (M/F, \%): 56/44 }\end{array}$ & $\begin{array}{l}\text { (1) Stroke occurrence } \\
\text { (2) NIHSS at admission } \\
\text { (all) } \\
(3) \text { Infarct size } \\
(n=134)\end{array}$ & $\begin{array}{l}\uparrow \mathrm{MBL} \text { associated with } \\
\text { stroke occurrence: } \\
\text { Area under ROC curve } \\
=0.76(0.71-0.83) \\
\text { MBL correlated mod- } \\
\text { erately with NIHSS } \\
\text { score }(r=0.70 \text {, } \\
p<0.0001) \text { and } \\
\text { weakly with infarct }^{1} \text { size }^{1}(r=0.49 \text {, } \\
p<0.001)\end{array}$ \\
\hline $\begin{array}{l}\text { Zangari et al }{ }^{88} \\
2016 \\
\text { Rating: Fair }\end{array}$ & $\begin{array}{l}\text { (1) Case-control: } \\
\text { Stroke occurrence } \\
\text { (2) Longitudinal: } \\
\text { Severity and outcome } \\
\text { after stroke } \\
\text { Blood sampling at } 6 \mathrm{~h} \\
\text { after admission } \\
\text { (cohort } 1 \text { ) or } 48 \text { h, } 4 \mathrm{~d} \\
\text { and } 1 \text { mo after admis- } \\
\text { sion (cohort 2) } \\
\text { Plasma MBL, ficolin-1, } \\
-2,-3 \text { (EDTA), ELISA }\end{array}$ & $\begin{array}{l}\text { Patients }(n=165) \\
\text { Two cohorts; different } \\
\text { blood sampling times } \\
\text { but same inclusion/ } \\
\text { exclusion criteria } \\
\text { (cohort } 1, n=80 \text {, } \\
\text { cohort } 2, n=85 \text { ) } \\
\text { Controls: next-of-kin's } \\
\text { to cases, matched on } \\
\text { age and gender } \\
(n=61 \text { ) } \\
\text { Follow-up: } 3 \text { months } \\
\text { Cohort } 1 / \text { cohort } 2: \\
\text { Age }>50: 94 \% \text { years } \\
\text { /86\% years } \\
\text { Gender (M/F, \%): } \\
41 / 59 \text { and } 58 / 42 \\
\text { Caucasian: } 100 \% \text { and } \\
96 \%\end{array}$ & $\begin{array}{l}\text { (1) Stroke occurrence } \\
\text { (2) NIHSS at admission } \\
\text { (3) Modified Rankin } \\
\text { Scale }\end{array}$ & $\begin{array}{l}\downarrow \text { ficolin- } 1 \text { and }-3 \\
\text { associated with stroke } \\
\text { Area under ROC curve } \\
=0.91 \text { for ficolin- } 1 \text { and } \\
0.68 \text { for ficolin-3 at } \\
6 \text { hour ( } 95 \% \text { Cls not } \\
\text { reported) } \\
\text { Ficolin- } 1 \text { at } 6 \text { h } \\
\text { improved prediction of } \\
\text { outcome (area under } \\
\text { ROC }=0.93 \text { [0.87- } \\
0.98] \text { vs. } 0.87 \text { [0.77- } \\
0.96] \text { for NIHSS }+ \text { age } \\
\text { alone) } \\
\text { Unfavourable out- } \\
\text { come associated with } \\
\downarrow \text { ficolin- } 1 \text { at } 6 \text { h } \\
\text { (adjusted OR }=2.21 \\
{[1.11-4.39] \text { ) but not }} \\
\text { ficolin-3 (OR = } 0.99 \\
{[0.93-1.05] \text { ) or other }} \\
\text { LP proteins (all } \\
p>0.05 \text { ) } \\
\text { No association } \\
\text { between LP and initial } \\
\text { stroke severity (data } \\
\text { not shown) }\end{array}$ \\
\hline $\begin{array}{l}\text { Song et al }{ }^{89} \\
2015 \\
\text { Rating: Good }\end{array}$ & $\begin{array}{l}\text { (1) Case-control: } \\
\text { Stroke occurrence } \\
\text { (2) Longitudinal: } \\
\text { Outcome after stroke } \\
\text { Blood sampling at first } \\
\text { morning after admis- } \\
\text { sion } \\
\text { Serum MBL, TRIFMA }\end{array}$ & $\begin{array}{l}\text { Patients with type } 2 \\
\text { diabetes }(n=188) \\
\text { Controls: healthy } \\
\text { volunteers, matched } \\
\text { for age and gender } \\
(n=100) \\
\text { Follow-up: } 1 \text { year } \\
\text { Age: } 68(57-79) \text { years } \\
\text { Gender (M/F, \%): } 56 / 44 \\
\text { Ethnicity: all Chinese }\end{array}$ & $\begin{array}{l}\text { (1) Stroke occurrence } \\
\text { (2) NIHSS at admission } \\
\text { (3) Modified Rankin } \\
\text { Scale } \\
\text { (4) All-cause mortality }\end{array}$ & $\begin{array}{l}\text { Unfavourable out- } \\
\text { come associated with } \\
\uparrow \mathrm{MBL} \\
\text { (adjusted OR }=8.99 \\
{[2.21-30.12], \text { area }} \\
\text { under ROC curve } \\
=0.75[0.68-0.83] \text { ) } \\
\uparrow \text { mortality associated } \\
\text { with } \uparrow \mathrm{MBL} \text { (adjusted } \\
\text { OR }=13.22 \text { [2.05- } \\
41.21] \text {, area under } \\
\text { ROC curve }=0.85 \\
{[0.80-0.90] \text { ) }} \\
\text { MBL correlated mod- } \\
\text { erately with NIHSS } \\
\text { score (Spearman, } \\
r=0.71, p=0.009 \text { ) }\end{array}$ \\
\hline
\end{tabular}


Table 5 (Continued)

\begin{tabular}{|c|c|c|c|c|}
\hline Author, year, rating & $\begin{array}{l}\text { Design } \\
\text { Lectin pathway para- } \\
\text { meters }\end{array}$ & Study population & $\begin{array}{l}\text { Endpoints for stroke } \\
\text { severity or outcome }\end{array}$ & Results \\
\hline $\begin{array}{l}\text { Zhang et al } \\
2015 \\
\text { Rating: Good }\end{array}$ & $\begin{array}{l}\text { (1) Case-control: } \\
\text { Stroke occurrence } \\
\text { (2) Longitudinal: } \\
\text { Outcome after stroke } \\
\text { Blood sampling at } \\
\text { admission } \\
\text { Serum MBL, ELISA }\end{array}$ & $\begin{array}{l}\text { Patients }(n=231) \\
\text { Controls: healthy } \\
\text { volunteers matched } \\
\text { for age and gender } \\
\text { ( } n=100) \\
\text { Follow-up: } 90 \text { days } \\
\text { ( } n=222 \text { completed } \\
\text { follow-up) } \\
\text { Good/poor outcome: } \\
\text { Age: } 61(55-73) \text { years } \\
\text { /69 } 61-76) \text { years } \\
\text { Gender (M/F, \%): } \\
62 / 38 \text { and } 60 / 40 \\
\text { Ethnicity: all Chinese }\end{array}$ & $\begin{array}{l}\text { (1) Stroke occurrence } \\
\text { (2) NIHSS at admission } \\
\text { (3) Modified Rankin } \\
\text { Scale } \\
\text { (4) All-cause mortality }\end{array}$ & $\begin{array}{l}\text { Unfavourable out- } \\
\text { come associated with } \\
\uparrow \mathrm{MBL} \text { (adjusted OR } \\
=5.28[2.88-10.67]) \\
\uparrow \text { mortality associated } \\
\text { with } \uparrow \mathrm{MBL} \text { (adjusted } \\
\mathrm{OR}=6.99 \text { [3.55- } \\
13.97]) \\
\text { MBL correlated weakly } \\
\text { with NIHSS score } \\
(r=0.33, p<0.001)\end{array}$ \\
\hline $\begin{array}{l}\text { Wang et } \text { al }^{91} \\
2014 \\
\text { Rating: Fair }\end{array}$ & $\begin{array}{l}\text { Case-control, blood } \\
\text { sampling at first } \\
\text { morning after admis- } \\
\text { sion } \\
\text { Serum MBL, TRIFMA }\end{array}$ & $\begin{array}{l}\text { Patients }(n=148) \\
\text { Controls: healthy } \\
\text { volunteers, matched } \\
\text { for age and gender } \\
(n=100) \\
\text { Cases: } \\
\text { Age: } 68(59-75) \text { years } \\
\text { Gender (M/F, \%): } 54 / 46 \\
\text { Ethnicity: all Chinese }\end{array}$ & $\begin{array}{l}\text { (1) NIHSS at admission } \\
\text { (all) } \\
\text { (2) Infarct size } \\
(n=112)\end{array}$ & $\begin{array}{l}\uparrow \mathrm{MBL} \text { in stroke versus } \\
\text { controls ( } 1,332 \text { vs. } 678 \\
\mu \mathrm{g} / \mathrm{L} \text {, multiple logistic } \\
\text { regression OR } \\
=1.002[1.001- \\
1.008]) \\
\uparrow \mathrm{MBL} \text { correlated } \\
\text { weakly with stroke } \\
\text { severity (Spearman, } \\
r=0.61, p=0.004) \\
\uparrow \mathrm{MBL} \text { with } \uparrow \text { infarct } \\
\text { size (ANOVA, } \\
p<0.0001) \\
\text { Area under ROC curve } \\
=0.76(0.70-0.82)\end{array}$ \\
\hline $\begin{array}{l}\text { Frauenknecht et al } \\
2013 \\
\text { Rating: Fair }\end{array}$ & $\begin{array}{l}\text { Case-control } \\
\text { Plasma- MASP-1, -2, -3, } \\
\text { MAp44 (citrate), } \\
\text { TRIFMA }\end{array}$ & $\begin{array}{l}\text { Patients }(n=66) \\
\text { Controls: healthy } \\
\text { volunteers }(n=50) \\
\text { and patients with } \\
\text { stable coronary artery } \\
\text { disease }(n=104) \\
\text { Stroke patients: } \\
\text { Age: } 65 \pm 16 \text { years } \\
\text { Gender }(M / F, \%): 62 / 38\end{array}$ & Stroke occurrence & $\begin{array}{l}\downarrow \text { MASP-2 in stroke } \\
\text { compared with con- } \\
\text { trols. } \\
\leftrightarrow \text { MASP-1, MASP-3 or } \\
\text { MAp44 between } \\
\text { groups ( } p>0.05)\end{array}$ \\
\hline $\begin{array}{l}\text { Füst et al } \\
2011 \\
\text { Rating: Poor }\end{array}$ & $\begin{array}{l}\text { (1) Case-control: } \\
\text { Stroke occurrence } \\
\text { (2) Longitudinal: } \\
\text { Outcome after stroke } \\
\text { Blood sampling at } 12 \mathrm{~h} \\
\text { and at 3-4 d after } \\
\text { admission } \\
\text { Serum ficolin-2 and -3, } \\
\text { ELISA }\end{array}$ & $\begin{array}{l}\text { Patients }(n=65) \\
\text { Controls: patients with } \\
\text { stable carotid artery } \\
\text { stenosis }(n=135) \text { and } \\
\text { healthy volunteers } \\
(n=100) \\
\text { Follow-up: until dis- } \\
\text { charge } \\
\text { Age: } 70 \pm 10 \text { years } \\
\text { Gender }(\mathrm{M} / \mathrm{F}, \%): 51 / 49\end{array}$ & $\begin{array}{l}\text { (1) NIHSS at admis- } \\
\text { sion, good }(<16) \text { ver- } \\
\text { sus poor }(\geq 16) \\
\text { (2) Modified Rankin } \\
\text { Scale at discharge }\end{array}$ & $\begin{array}{l}\text { Unfavourable out- } \\
\text { come associated with } \\
\downarrow \text { ficolin-3 at day } 3 \\
(\mathrm{OR}=5.63[1.50- \\
21.15]) \\
\text { No difference in mean } \\
\text { ficolin-2 between out- } \\
\text { come groups, } \\
p=0.30, \text { OR not } \\
\text { computed } \\
\text { Poor NIHSS associated } \\
\text { with } \uparrow \text { ficolin-3 at day } 3 \\
(p=0.02) \text {, but not at } \\
\text { admission } \\
\text { No association } \\
\text { between NIHSS and } \\
\text { ficolin- } 2(p=0.30)\end{array}$ \\
\hline $\begin{array}{l}\text { Osthoff et al } \\
2011 \\
\text { Rating: Good }\end{array}$ & $\begin{array}{l}\text { Longitudinal, blood } \\
\text { sampling at admission } \\
\text { Serum MBL, ELISA }\end{array}$ & $\begin{array}{l}\text { Patients receiving } \\
\text { either conservative } \\
\text { treatment }(n=287) \\
\text { or thrombolysis } \\
(n=66)\end{array}$ & $\begin{array}{l}\text { (1) Stroke severity: } \\
\text { NIHSS at admission } \\
\text { (all), infarct size (in } \\
199 \text { patients) } \\
\text { (2) Modified Rankin }\end{array}$ & $\begin{array}{l}\text { Conservative treat- } \\
\text { ment group: } \\
\text { Unfavourable out- } \\
\text { come associated with } \\
\uparrow \mathrm{MBL} \text { : }\end{array}$ \\
\hline
\end{tabular}


Table 5 (Continued)

\begin{tabular}{|c|c|c|c|c|}
\hline Author, year, rating & $\begin{array}{l}\text { Design } \\
\text { Lectin pathway para- } \\
\text { meters }\end{array}$ & Study population & $\begin{array}{l}\text { Endpoints for stroke } \\
\text { severity or outcome }\end{array}$ & Results \\
\hline & & $\begin{array}{l}\text { Follow-up: } 90 \text { days } \\
\text { Age: } 75(63-82) \text { years } \\
\text { Gender (M/F, \%): 59/41 }\end{array}$ & $\begin{array}{l}\text { Scale } \\
\text { (3) Barthel Index }\end{array}$ & $\begin{array}{l}\text {-Rankin Scale } \\
\text { (adjusted OR }=1.23 \\
{[1.02-1.48] \text { for con- }} \\
\text { tinuous serum MBL } \\
\text { and } 0.38[0.14-0.98] \\
\text { in low vs. high MBL) } \\
\text {-Barthel Index } \\
\text { (adjusted OR }=1.26 \\
(1.04-1.54 \text { ) for con- } \\
\text { tinuous data) } \\
\uparrow \text { severity and } \uparrow \text { infarct } \\
\text { size associated with } \uparrow \\
\text { MBL ( } p=0.025 \text { and } \\
0.003 \text { ) } \\
\text { No associations in } \\
\text { thrombolysis group } \\
\text { (no difference in med- } \\
\text { ian MBL between out- } \\
\text { come or severity } \\
\text { groups, all } p>0.50 \text { ) }\end{array}$ \\
\hline $\begin{array}{l}\text { Cervera et } \text { al }^{94} \\
2010 \\
\text { Rating: Good }\end{array}$ & $\begin{array}{l}\text { Longitudinal } \\
\text { MBL2 genotype } \\
\text { Promoter -221, codon } \\
\text { 52, 54, } 57 \\
\text { MASP2 SNP D120G } \\
\text { Serum MBL, MASP-2, } \\
\text { ELISA }\end{array}$ & $\begin{array}{l}\text { Patients with ischae- } \\
\text { mic }(n=109) \text { or hae- } \\
\text { morrhagic }(n=26) \\
\text { stroke } \\
\text { Follow-up: } 90 \text { days } \\
\text { Low/high MBL: } \\
\text { Age: } 74 \pm 13 \text { years } \\
/ 73 \pm 12 \text { years } \\
\text { Gender }(\mathrm{M} / \mathrm{F}, \%) \text { : } \\
38 / 62 \text { and } 53 / 47\end{array}$ & $\begin{array}{l}\text { Favourable versus } \\
\text { unfavourable out- } \\
\text { come, 'favourable' } \\
\text { defined as modified } \\
\text { Rankin Scale }<2 \text {, } \\
\text { NIHSS score }<2 \text { and } \\
\text { Barthel Index } \geq 95 \%\end{array}$ & $\begin{array}{l}\text { Unfavourable out- } \\
\text { come associated with } \\
\uparrow \text { serum MBL (adjusted } \\
\text { OR }=1.29 \text { [1.02- } \\
1.69] \text { ) and high geno- } \\
\text { type (adjusted OR } \\
=10.85[1.87-62.94] \text { ) } \\
\text { No association } \\
\text { between MASP2 poly- } \\
\text { morphism and out- } \\
\text { come }(\mathrm{OR}=0.92 \\
[0.23-3.73])\end{array}$ \\
\hline
\end{tabular}

Abbreviations: $\mathrm{Cl}$, confidence interval; $\mathrm{CT}$, computed tomography; EDTA, ethylenediaminetetraacetic acid; ELISA, enzyme-linked immunosorbent assay; LP, lectin pathway; MASP, MBL-associated serine protease; MBL, mannose-binding lectin; MBL2, gene encoding MBL; MRI, magnetic resonance imaging; NIHSS, National Institutes of Health Stroke Scale; OR, odds ratio; ROC, receiver operator characteristics; TRIFMA, time-resolved immunofluorometric assay; WHO, World Health Organization.

Note: Study population: 'Patients' refer to patients with ischaemic stroke (cases) unless otherwise specified. Stroke was verified with CT/MRI or according to the WHO criteria for all studies. Age, gender and ethnicity are stated if reported in the study. Age is rounded to whole years and indicated by mean \pm standard deviation or median (interquartiles) unless otherwise specified. Endpoints: All studies defined 'favourable' outcome as Rankin Scale $<2$ points or Barthel Index $\geq 95 \%$. Results: Numbers in parentheses after OR/HR/area under ROC curve are $95 \%$ confidence intervals unless otherwise specified.

hypercholesterolaemia, ${ }^{71}$ rheumatoid arthritis, ${ }^{37,68}$ endstage kidney disease ${ }^{66}$ or pancreas-kidney transplantion. ${ }^{69}$ Thus, the study populations were heterogeneous, and we summarize their main findings here with this limitation in mind.

Overall, the reported associations between MBL and CVE occurrence varied considerably between studies with regards to effect size as well as direction. Two case-control studies found that CVE occurrence was associated with increased MBL serum levels ${ }^{74,75}$ and high genotype. ${ }^{74}$ This was supported by prospective studies, which all reported increased CVE occurrence in patients with high serum MBL levels ${ }^{69,70}$ or high genotype; ${ }^{37,68}$ however, Keller et al only found this association in a sub-population of men. ${ }^{70}$ In contrast to this increased CVE risk related to high MBL, three studies reported that CVE was associated with low
MBL, 66,67,71 although Saevarsdottir et al only found this association in sub-groups with hypercholesterolaemia and diabetes. ${ }^{71}$ It was possible to extract/obtain data from six studies investigating serum MBL and five studies investigating MBL2 genotype to perform forest plots of crude or adjusted odds ratios for CVE with high serum MBL or high genotype ( - Fig. 4). The forest plots support that high serum MBL or genotype was not consistently associated with a higher CVE risk in the included studies.

Regarding other lectin pathway proteins, no clear patterns emerged. Two studies reported higher MASP-1 levels in patients with MI compared with healthy controls; ${ }^{84,95}$ two studies found lower MASP-2 levels in patients with MI versus healthy controls; ${ }^{76,95}$ and finally, two studies reported associations between MI and higher MASP-3 levels. ${ }^{73,84}$ Vengen et al also found MI to be associated with higher ficolin-2 
Table 6 The lectin pathway in other pro-thrombotic conditions

\begin{tabular}{|c|c|c|c|c|}
\hline Author, year, rating & $\begin{array}{l}\text { Design } \\
\text { Lectin pathway } \\
\text { parameters }\end{array}$ & Study population & $\begin{array}{l}\text { Endpoints for throm- } \\
\text { boembolic disease or } \\
\text { coagulation activity }\end{array}$ & Results \\
\hline \multicolumn{5}{|c|}{ Systemic lupus erythematosus (SLE) } \\
\hline $\begin{array}{l}\text { Kozarcanin et al }{ }^{61} \\
2016 \\
\text { Rating: Fair }\end{array}$ & $\begin{array}{l}\text { Cross-sectional } \\
\text { MASP-1/-2 activation } \\
\text { (MASP-1/-2 in complex } \\
\text { with C1-inhibitor or } \\
\text { anti-thrombin) }\end{array}$ & $\begin{array}{l}\text { Patients: } \operatorname{SLE}(n=69) \text {, } \\
\text { multi-trauma }(n=10) \\
\text { Trauma: } \\
\text { Age: } 23-80 \text { years } \\
\text { Gender }(M / F, \%): 80 / 20\end{array}$ & $\begin{array}{l}\text { SLE: Platelet activation } \\
\text { markers, platelet } \\
\text { count, FXla, FXIla } \\
\text { Trauma: Platelet } \\
\text { count, PT, aPTT, TAT- } \\
\text { complex and } \\
\text { fibrinogen }\end{array}$ & $\begin{array}{l}\text { SLE: Positive correla- } \\
\text { tion between MASP } \\
\text { complexes and plate- } \\
\text { let activation, FXIa and } \\
\text { FXIla (rho values, } \\
0.31-0.74 \text {, all } \\
p<0.001 \text { ) } \\
\text { Trauma: Positive cor- } \\
\text { relation between } \\
\text { MASP complexes and } \\
\text { PT, TAT-complex and } \\
\text { fibrinogen, but not } \\
\text { aPTT or platelet count }\end{array}$ \\
\hline $\begin{array}{l}\text { Hein et } \mathrm{al}^{41} \\
2015 \\
\text { Rating: Poor }\end{array}$ & $\begin{array}{l}\text { Cross-sectional } \\
\text { Plasma ficolin-1, -2, }-3 \\
\text { (EDTA), ELISA }\end{array}$ & $\begin{array}{l}\text { Patients: } \operatorname{SLE}(n=68) \\
\text { Age: } 40 \text { (range: } 21- \\
76) \text { years } \\
\text { Gender (M/F,\%): } 9 / 91\end{array}$ & $\begin{array}{l}\text { History of arterial or } \\
\text { venous thrombosis }\end{array}$ & $\begin{array}{l}\uparrow \text { ficolin- } 1 \text { in patients } \\
\text { with a history of arter- } \\
\text { ial thrombosis } \\
\text { ( } p=0.005) \\
\text { No difference in ficolin- } \\
2 \text { or }-3 \text { for arterial } \\
\text { thrombosis and no } \\
\text { difference for venous } \\
\text { thrombosis (all } \\
p>0.05)\end{array}$ \\
\hline $\begin{array}{l}\text { Jönsen et al } \\
2007 \\
\text { Rating: Good }\end{array}$ & $\begin{array}{l}\text { Longitudinal } \\
\text { MBL2 genotype } \\
\text { Promoter }-550,-221 \text {, } \\
\text { codon } 52,54,57\end{array}$ & $\begin{array}{l}\text { Patients: SLE } \\
(n=143) \\
\text { Mean follow-up: } 15 \\
\text { years } \\
\text { Age at enrolment not } \\
\text { reported } \\
\text { Gender (M/F, \%): } 12 / 88\end{array}$ & $\begin{array}{l}\text { Cerebrovascular, cor- } \\
\text { onary or peripheral } \\
\text { vascular event }\end{array}$ & $\begin{array}{l}\text { No association } \\
\text { between MBL2 geno- } \\
\text { type and thrombotic } \\
\text { events (adjusted OR } \\
=3.3[0.80-14] \text { ) }\end{array}$ \\
\hline $\begin{array}{l}\text { Font et al } \\
2007 \\
\text { Rating: Fair }\end{array}$ & $\begin{array}{l}\text { Cross-sectional } \\
\text { MBL2 genotype } \\
\text { Promoter }-550,-221, \\
\text { UTR }+4 \text {, codon } 52,54 \text {, } \\
57\end{array}$ & $\begin{array}{l}\text { Patients: SLE } \\
(n=114) \\
\text { Age: } 41 \pm 1 \text { years } \\
\text { Gender }(\mathrm{M} / \mathrm{F}, \%): 7 / 93\end{array}$ & $\begin{array}{l}\text { Previous cerebrovas- } \\
\text { cular thrombosis } \\
\text { (arterial or venous), } \\
\text { MI, intra-abdominal } \\
\text { artery thrombosis, } \\
\text { DVT or PE }\end{array}$ & $\begin{array}{l}\text { No association } \\
\text { between MBL2 geno- } \\
\text { type and thrombotic } \\
\text { events in multivariate } \\
\text { analysis (OR not } \\
\text { reported) }\end{array}$ \\
\hline $\begin{array}{l}\text { Calvo-Alén et al }{ }^{98} \\
2006 \\
\text { Rating: Fair }\end{array}$ & $\begin{array}{l}\text { Longitudinal } \\
\text { MBL2 genotype } \\
\text { Codon 52, 54, } 57\end{array}$ & $\begin{array}{l}\text { Patients: SLE } \\
(n=415) \\
\text { Mean follow-up: } 3.9 \\
\text { years } \\
\text { Thrombosis: yes/no } \\
\text { Age: } 44 \pm 15 \text { years } \\
\text { /36 } \pm 12 \text { years } \\
\text { Gender (M/F, \%): } \\
17 / 83 \text { and } 9 / 91 \\
\text { Ethnicity: } \\
\text { Hispanic: } 23 \% \text { and } 30 \% \\
\text { African: } 40 \% \text { and } 40 \% \\
\text { Caucasian: } 37 \% / 30 \%\end{array}$ & $\begin{array}{l}\text { MI, angina pectoris, } \\
\text { CABG, } \\
\text { ischaemic stroke, } \\
\text { transient ischaemic } \\
\text { attack or } \\
\text { peripheral vascular } \\
\text { disease }\end{array}$ & $\begin{array}{l}\text { No significant associa- } \\
\text { tion between MBL2 } \\
\text { genotype and throm- } \\
\text { botic events, except } \\
\text { cerebrovascular } \\
\text { events alone: } \uparrow \text { events } \\
\text { in low versus inter- } \\
\text { mediate/high geno- } \\
\text { type }(p=0.049)\end{array}$ \\
\hline $\begin{array}{l}\text { Øhlenschlaeger et al } \\
2004 \\
\text { Rating: Good }\end{array}$ & $\begin{array}{l}\text { Longitudinal } \\
\text { MBL2 genotype } \\
\text { Promoter }-550,-221 \text {, } \\
\text { codon } 52,54,57\end{array}$ & $\begin{array}{l}\text { Patients: SLE }(n=91) \\
\text { Mean follow-up: } 11 \\
\text { years } \\
\text { Gender (M/F, \%): } 10 / 90 \\
\text { Ethnicity: Caucasian }\end{array}$ & $\begin{array}{l}\text { MI, cerebrovascular } \\
\text { event, } \\
\text { peripheral vascular } \\
\text { disease, DVT or PE }\end{array}$ & $\begin{array}{l}\uparrow \text { arterial events in } \\
\text { patients with low ver- } \\
\text { sus intermediate/high } \\
\text { genotype (adjusted } \\
\mathrm{HR}=7.0[1.9-25.4] \text { ) } \\
\text { No association } \\
\text { between genotype } \\
\text { and venous thrombo- } \\
\text { sis (data not shown) }\end{array}$ \\
\hline
\end{tabular}


Table 6 (Continued)

\begin{tabular}{|c|c|c|c|c|}
\hline Author, year, rating & $\begin{array}{l}\text { Design } \\
\text { Lectin pathway } \\
\text { parameters }\end{array}$ & Study population & $\begin{array}{l}\text { Endpoints for throm- } \\
\text { boembolic disease or } \\
\text { coagulation activity }\end{array}$ & Results \\
\hline \multicolumn{5}{|c|}{ Disseminated intravascular coagulation (DIC) } \\
\hline $\begin{array}{l}\text { Sprong et } \text { al }^{103} \\
2009 \\
\text { Rating: Fair }\end{array}$ & $\begin{array}{l}\text { Cross-sectional } \\
\text { MBL2 genotype } \\
\text { Codon } 52,54,57\end{array}$ & $\begin{array}{l}\text { Patients: septic shock } \\
(n=18) \\
\text { Age: } 6 \text { months-7 years } \\
\text { Gender (M/F, \%): } 50 / 50\end{array}$ & $\begin{array}{l}\text { Platelet count, fibrino- } \\
\text { gen, ISTH DIC score }\end{array}$ & $\begin{array}{l}\uparrow \text { platelet count and } \\
\text { fibrinogen and } \downarrow \text { DIC } \\
\text { score in children with } \\
\text { low genotype }(n=2)\end{array}$ \\
\hline $\begin{array}{l}\text { Zhao et al } \\
2015 \\
\text { Rating: Good }\end{array}$ & $\begin{array}{l}\text { (1) Cross-sectional: } \\
\text { DIC at admission } \\
\text { (2) Longitudinal: } \\
\text { DIC development after } \\
\text { admission } \\
\text { Blood sampling at } \\
\text { admission } \\
\text { Serum MBL, ELISA }\end{array}$ & $\begin{array}{l}\text { Patients: sepsis with/ } \\
\text { without shock } \\
(n=267) \\
\text { Follow-up: until dis- } \\
\text { charge } \\
\text { DIC/no DIC at admis- } \\
\text { sion: } \\
\text { Age: } 67 \pm 15 \text { years } \\
/ 68 \pm 14 \text { years } \\
\text { Gender }(M / F, \%): \\
61 / 39 \text { and } 60 / 40\end{array}$ & $\begin{array}{l}\text { Overt DIC (ISTH DIC } \\
\text { score } \geq 5 \text { ) at admission } \\
\text { or developed during } \\
\text { hospitalization, } \\
\text { assessed once daily }\end{array}$ & $\begin{array}{l}\text { MBL did not predict } \\
\text { DIC independently (OR } \\
\text { or area under ROC } \\
\text { curve not reported) } \\
\uparrow \mathrm{MBL} \text { in DIC versus no } \\
\text { DIC (125 vs. } 116 \mathrm{ng} / \mathrm{L} \text {, } \\
p=0.007)\end{array}$ \\
\hline $\begin{array}{l}\text { Takahashi et al } \\
2014 \\
\text { Rating: Good }\end{array}$ & $\begin{array}{l}\text { Case-control } \\
\text { Plasma CL-K1 (citrate), } \\
\text { ELISA }\end{array}$ & $\begin{array}{l}\text { Patients: DIC of differ- } \\
\text { ent aetiology } \\
(n=549) \\
\text { Controls: Patients } \\
\text { without DIC }(n=82) \\
\text { and healthy controls } \\
(n=27) \\
\text { DIC/no DIC: } \\
\text { Age: } 67(53-78) \text { years } \\
\text { /64 (51-73) years } \\
\text { Gender (M/F, \%): } \\
56 / 44 \text { and 60/40 } \\
\text { Ethnicity: Caucasian }\end{array}$ & $\begin{array}{l}\text { DIC: biphasic aPTT } \\
\text { waveform present }\end{array}$ & $\begin{array}{l}\text { DIC associated with } \uparrow \\
\text { CL-K1 }(\mathrm{OR}=1.93 \\
[1.04-3.87])\end{array}$ \\
\hline \multicolumn{5}{|l|}{ Others } \\
\hline $\begin{array}{l}\text { Lv et al }{ }^{100} \\
2013 \\
\text { Rating: Poor }\end{array}$ & $\begin{array}{l}\text { Case-control } \\
\text { LP mRNA expression } \\
\text { (whole genome } \\
\text { expression) }\end{array}$ & $\begin{array}{l}\text { Patients: PE }(n=20) \\
\text { Controls: patients } \\
\text { without PE matched } \\
\text { for age and gender } \\
(n=20) \\
\text { Cases: } \\
\text { Age: } 70 \pm 14 \text { y } \\
\text { Gender (M/F, \%): } 55 / 45\end{array}$ & $\mathrm{PE}$ & $\begin{array}{l}\downarrow \text { mRNA expression } \\
\text { for MBL and MASP- } 1 \text { in } \\
\text { PE versus controls } \\
(p<0.05) ; \text { no differ- } \\
\text { ence for MASP- } 2 \text { ( } p \text { - } \\
\text { value not reported) }\end{array}$ \\
\hline $\begin{array}{l}\text { Merlen et al }{ }^{101} \\
2015 \\
\text { Rating: Fair }\end{array}$ & $\begin{array}{l}\text { Longitudinal, blood } \\
\text { sampling before ther- } \\
\text { apy and every } 3 \text { wk } \\
\text { until end of therapy } \\
\text { Serum MBL, EIA }\end{array}$ & $\begin{array}{l}\text { Patients: acute lym- } \\
\text { phoblastic leukaemia } \\
\text { receiving L-asparagi- } \\
\text { nase }(n=97) \\
\text { Follow-up: } 25 \text { wk } \\
\text { Age: } 6.4 \text { (range: } 1-17 \text { ) } \\
\text { years } \\
\text { Gender (M/F, \%): 56/44 }\end{array}$ & $\begin{array}{l}\text { Plasma-fibrinogen and } \\
\text {-anti-thrombin }\end{array}$ & $\begin{array}{l}\downarrow \mathrm{MBL} \text {, fibrinogen and } \\
\text { anti-thrombin during } \\
\text { therapy versus base- } \\
\text { line } \\
\text { MBL levels correlated } \\
\text { moderately with fibri- } \\
\text { nogen (Spearman, } \\
r=0.58, p<0.0001) \\
\text { and anti-thrombin } \\
(r=0.40, p<0.0001)\end{array}$ \\
\hline
\end{tabular}

Abbreviations: aPTT, activated partial thromboplastin time; CABG, coronary artery bypass grafting; CL-K1, collectin kidney 1; DIC, disseminated intravascular coagulation; DVT, deep vein thrombosis; EDTA, ethylenediaminetetraacetic acid; ELISA, enzyme-linked immunosorbent assay; EIA, enzyme immunoassay; F, coagulation factor; HR, hazard ratio; ISTH, International Society on Thrombosis and Haemostasis; LP, lectin pathway; MASP, MBL-associated serine protease; MBL, mannose-binding lectin; MBL2, gene encoding MBL; MI, myocardial infarction; mRNA, messenger ribonucleic acid; OR, odds ratio; PE, pulmonary embolism; PT, prothrombin time; SLE, systemic lupus erythematosus; ROC, receiver operator characteristics; TAT, thrombin-anti-thrombin.

Note: Study population: Age, gender and ethnicity are stated if reported in the study. Age is rounded to whole years and indicated by mean \pm standard deviation or median (interquartiles) unless otherwise specified. Results: Numbers in parentheses after OR/HR/area under ROC curve are $95 \%$ confidence intervals unless otherwise specified. 

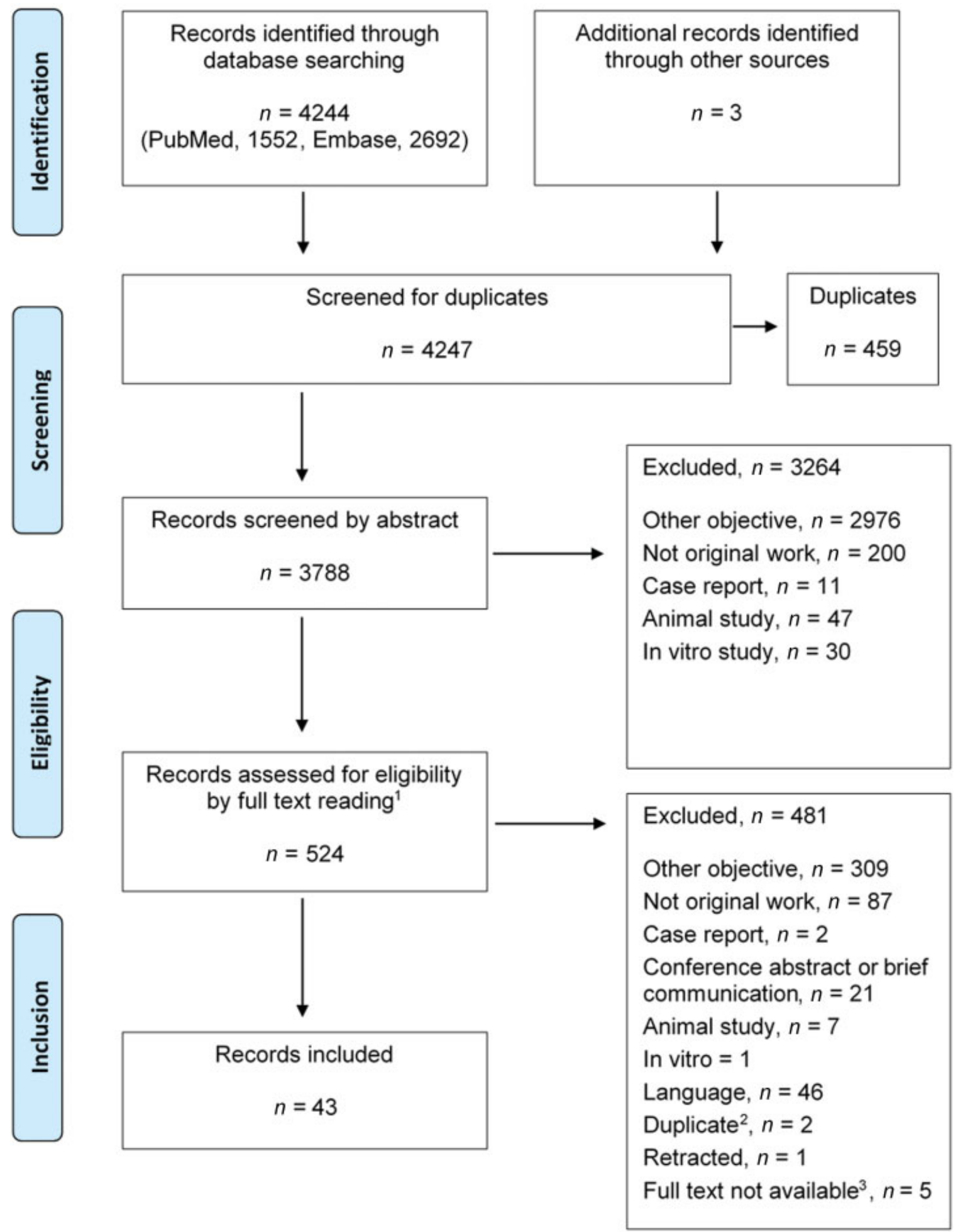

Fig. 3 Inclusion and exclusion process. Notes: ${ }^{1}$ Including 378 with no available abstract; ${ }^{2}$ Duplicate not caught in initial duplicate screening; ${ }^{3}$ Could not be obtained via the Aarhus University Library/Royal Danish Library.

levels, ${ }^{73}$ while Schoos et al reported the opposite..$^{83}$ No associations between ficolin-1 or -3 and CVE were observed. ${ }^{72,73,83}$

Four studies analysed MAp44, of which three found no association between this protein and CVE, ${ }^{45,73,95}$ while one study reported increased MAp44 levels in MI patients versus healthy controls. ${ }^{84}$
The Lectin Pathway and Outcome in Existing Cardiovascular Disease

The nine studies investigating the association between lectin pathway proteins and outcome in patients with pre-existing CVE are presented in - Table 4. All studies included study populations with recent MI; most having undergone either CABG or PCI in the early phase of the study. The following 


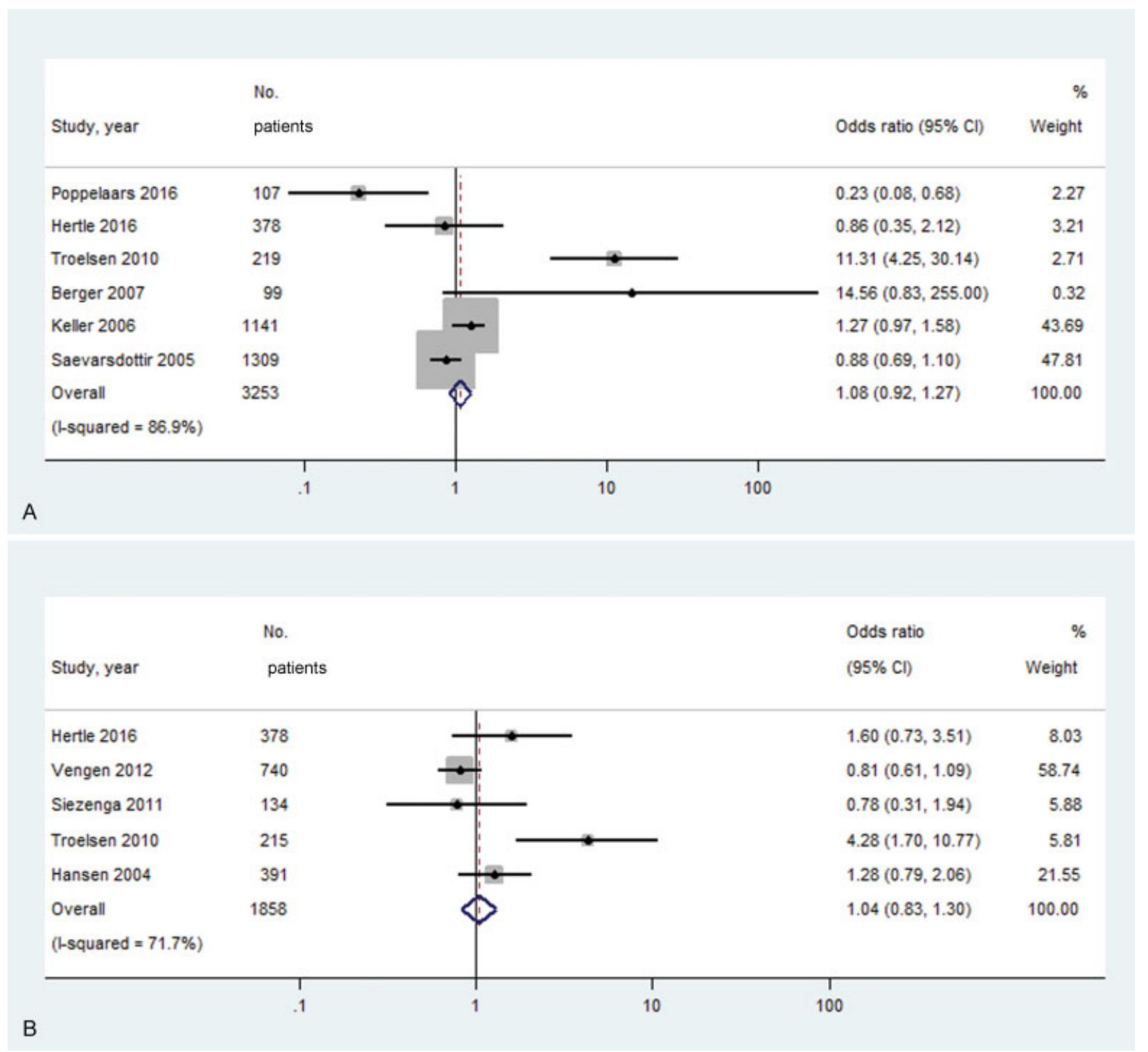

Fig. 4 Forest plots of odds ratios for cardiovascular events with (A) high versus low serum levels of mannose-binding lectin (MBL) and (B) MBL2 genotype associated with high (wild-type) versus intermediate or MBL serum level. Dotted vertical lines represent pooled or overall odds ratio.

endpoints for outcome or severity of CVE were investigated: recurrent $\mathrm{MI},{ }^{80,81}$ reduced left ventricle ejection fraction (heart failure), ${ }^{79,83}$ change in end-systolic/-diastolic volume, ${ }^{83}$ infarct size, ${ }^{83}$ myocardial salvage index, ${ }^{84}$ early CABG venous graft occlusion, ${ }^{82}$ CVE-related mortality, allcause mortality ${ }^{81}$ or a composite endpoint consisting of two or more of these. ${ }^{77,78,85}$

Three studies reported that low serum MBL or low genotype was associated with a better outcome after MI. ${ }^{78-80}$ In contrast, two studies found an association between low MBL and early recurrent $\mathrm{MI}^{81}$ or graft occlusion after $C A B G,{ }^{82}$ while Mellbin et al found no association between MBL or MASP-2 and CVE. ${ }^{77,85}$ Holt et al investigated MASP-1, MASP-3 and MAp44 and found no association between either of these proteins and myocardial salvage after $\mathrm{PCI} .{ }^{84}$ Schoos et al demonstrated no association between MAp44 alone and cardiac function either, but reported that both high ficolin-2 alone and a combination of high ficolin and low MAp44 were associated with impaired cardiac function (higher end-systolic and end-diastolic volumes). ${ }^{83}$

\section{Ischaemic Stroke}

The Lectin Pathway and Occurrence of Ischaemic Stroke

Eight case-control studies investigated lectin pathway patients with ischaemic stroke versus healthy controls. ${ }^{86-92,95}$ In general, stroke was diagnosed according to valid diagnostic criteria and/or verified with radiological imaging. Among the five studies analysing MBL, four studies reported higher serum MBL levels in stroke patients compared with healthy controls. ${ }^{87,89-91}$ High MBL was moderately associated with the occurrence of stroke with areas under the receiver operator characteristics (ROC) curves $=0.76 .{ }^{87,91}$ In contrast, one study found no association between plasma MBL and ischaemic stroke. ${ }^{88}$ 
Zangari et al found lower levels of ficolin-1, -2 and -3 during the early phase of stroke and a strong association between low ficolin-1 at 6 hours and stroke occurrence (area under the ROC curve $=0.91) .{ }^{88}$ This was in accordance with Füst et al who also reported low ficolin-2 and -3 levels at admission in stroke patients. ${ }^{92}$ Frauenknecht et al found lower levels of MASP-2 in stroke patients compared with controls, but demonstrated no difference for MASP-1, -3 or MAp44. ${ }^{95}$

The Lectin Pathway and Functional Outcome or Severity of Stroke

The following endpoints were used for stroke severity and functional outcome after stroke: initial stroke severity assessed with National Institute of Health Stroke Scale $(\mathrm{NIHSS})^{86-93}$ where increasing score indicates increasing stroke severity, infarction volume estimated with magnetic resonance imaging, ${ }^{87,91,93}$ functional outcome assessed with modified Rankin Scale ${ }^{88-90,92,93}$ or Barthel Index ${ }^{93}$ or a composite endpoint of NIHSS, modified Rankin Scale and Barthel Index. ${ }^{94} \mathrm{~A}$ favourable outcome on the Rankin Scale was typically defined as $<2$ points and on the Barthel Index as $>95 \%$.

In general, the studies demonstrated an association between high MBL and increased stroke severity and unfavourable outcome. MBL was reported to correlate positively

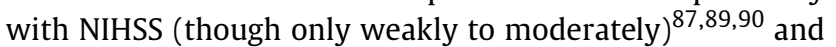
with infarct size. ${ }^{91}$ Several studies found that high MBL was independently associated with both higher mortality and unfavourable outcome on Rankin Scale $e^{89,90,93}$ and Barthel Index. ${ }^{93}$ The only study investigating MBL2 genotype supported these findings, reporting that both high serum MBL and high genotype was associated with an unfavourable outcome. ${ }^{94}$ Song et al calculated the ability of MBL to predict mortality and functional outcome, finding moderate areas under the ROC curves ( 0.85 for mortality and 0.75 for Rankin Scale). ${ }^{89}$ Only one study did not find an association between MBL and stroke severity or functional outcome. ${ }^{88}$

With regards to other lectin pathway proteins, Kouchaki et al found a significant positive correlation between ficolin1 and NIHSS score, ${ }^{86}$ indicating that high ficolin- 1 levels are associated with more severe stroke. This contrasted with Zangari et al who found no association between ficolins and NIHSS score, but reported an association between low ficolin- 1 and unfavourable outcome on modified Rankin Scale. ${ }^{88}$ Füst et al found that low ficolin-3 at day 3 after stroke was associated with unfavourable outcome, but also with less initial stroke severity. ${ }^{92}$

\section{Other Conditions}

\section{Systemic Lupus Erythematosus}

Four studies examined associations between MBL2 genotypes and thrombotic events in SLE patients. ${ }^{96-99}$ Øhlenschlaeger et al reported that low genotype was associated with increased risk of arterial thrombosis, defined as cardiovascular, cerebrovascular or peripheral vascular events, but not with venous thrombosis. ${ }^{99}$ The three remain- ing studies found no independent association ${ }^{96,97}$ or only a borderline significant association ${ }^{98}$ between $M B L 2$ genotype and thrombotic events.

Hein et al reported that SLE patients with a history of arterial but not venous thrombosis had significantly higher circulating ficolin-1 levels. ${ }^{41}$ The method for verifying a previous thrombotic event was not reported, nor could it be found in the original source cited. Kozarcanin et al did not include clinical endpoints, but investigated correlations between MASP-1 and -2 activation and platelet and coagulation parameters in SLE patients and multi-trauma patients. ${ }^{61}$ The authors reported that MASP activation correlated significantly with activation of both primary and secondary haemostasis in both patient groups.

\section{Disseminated Intravascular Coagulation}

Sprong et al investigated the association between MBL2 genotype and coagulation parameters and clinical manifestations indicating DIC in children with meningococcal disease and septic shock. ${ }^{103}$ Children with low genotype ( $n=2$ of 18) had a lower DIC score, and their platelet counts and fibrinogen levels were markedly closer to the normal range compared with children with intermediate or high genotype. Due to the small number of patients, statistical significance was not calculated. In a study on adult sepsis patients, Zhao et al reported higher MBL levels in patients with overt DIC at admission and in patients who developed DIC later compared with patients without DIC, but MBL was not found to be an independent predictor for the development of DIC. ${ }^{104}$ In both the DIC and non-DIC group, the mean MBL serum level was well below the range reported by other authors in healthy individuals, ${ }^{21}$ and the difference between the DIC and nonDIC group, although statistically significant, was subtle. Finally, Takahashi et al investigated CL-K1 in 549 patients with DIC of various aetiologies and found that DIC was associated with higher CL-K1 levels. ${ }^{102}$

\section{Other Studies}

Lv et al conducted a case-control study in patients with pulmonary embolism and healthy controls and extensively investigated complement-related messenger ribonucleic acid (mRNA) expression. ${ }^{100}$ They found lower expression of MBL2 and MASP2 mRNA in patients with pulmonary embolism compared with healthy controls.

Finally, Merlen et al investigated serum-MBL, fibrinogen, anti-thrombin and thrombotic events in paediatric patients who were treated with L-asparaginase, ${ }^{101}$ a chemotherapeutic drug with a known pro-thrombotic effect. The main finding related to the scope of the present review was that MBL correlated positively, although only weakly, with both fibrinogen and anti-thrombin.

\section{Discussion}

The present systematic review did not reveal a consistent association between the lectin pathway and thrombotic conditions. MBL serum levels and/or genotype were the most commonly investigated lectin pathway parameters. 
An association between MBL and CVE occurrence or outcome was observed in several studies but differed in both effect size and direction. In ischaemic stroke patients, high serum MBL was consistently associated with occurrence of stroke as well as increased stroke severity and unfavourable outcome. Only few studies on other thrombotic conditions were identified.

In general, the included studies were of high quality, with $90 \%$ rating 'good' or 'fair' using the National Institute of Health quality assessment tools. This indicates a low risk of bias and overall high validity of the results. Among the 43 studies, 29 (67\%) were prospectively designed, while the rest was cross-sectional or case-control studies. CVE $(n=23)$, ischaemic stroke $(n=10)$, SLE-associated thrombosis $(n=6)$ and sepsis-associated DIC $(n=3)$ were the most commonly investigated thrombotic conditions. Almost all studies had clinical thromboembolic disease as their main outcome, and only five studies used laboratory coagulation parameters as endpoints. ${ }^{61,101-104}$ A variety of materials (serum, ethylenediaminetetraacetic acid plasma, citrated plasma) were used for lectin pathway protein analysis, as well as different assays (enzyme-linked immunosorbent assay, time-resolved immunofluorometric assay); however, there did not seem to be an association between the materials or assays used and the reported results.

As summarized in the introduction, the available in vitro evidence consistently reports that MBL and MASP-1 and -2 can activate the coagulation system. This is supported by animal studies. Studies on induced carotid artery and cerebral thrombosis in murine models found that MBL-deficient mice had preserved carotid blood flow ${ }^{105,106}$ and less intravascular fibrin deposition ${ }^{107}$ compared with wild-type mice. Takahashi et al demonstrated a prolonged tail bleeding time in MBL-deficient mice which could be restored with recombinant MBL. Taken together, the available evidence from in vitro and animal studies thus suggests a pro-coagulant effect of lectin pathway activation and a protective role of MBL deficiency on thrombus development.

The results of the present systematic review do not unequivocally support these findings of in vitro and animal studies. The included studies reported conflicting results, especially regarding the role of the lectin pathway in cardiovascular thrombosis. Both high ${ }^{37,69}$ and low ${ }^{66,67}$ MBL levels were reported to be risk factors for CVE, while two large cohort studies found no overall influence of serum MBL on future CVE risk. ${ }^{70,71}$ A probable explanation of these conflicting results could be the diversity in study populations; they all carried an increased CVE risk but differed with regards to the underlying pathophysiology and baseline risk of thrombotic events. Furthermore, follow-up times varied, and a variety of endpoints or combinations of endpoints were employed.

The studies on ischaemic stroke more consistently reported associations between high MBL levels and stroke occurrence as well as severity ${ }^{87,89-91,93}$ with a single exception. $^{88}$ The ficolins were investigated in three studies only. ${ }^{86,88,92}$ Associations between both ficolin-1 and ficolin-3 and stroke severity and long-term outcome were described; however, the findings were contrasting, and the scarcity of studies make it difficult to conclude on the role of ficolins in ischaemic stroke. An association between high MBL and unfavourable outcome was also consistently reported after stroke, ${ }^{89,90,93,94}$ again with one exception, ${ }^{88}$ as recently reviewed by Fumagalli and De Simoni, ${ }^{108}$ but this association was not consistently reported after MI. ${ }^{77-83}$ An important point is that the functional outcome after an ischaemic event is not only related to the thrombus itself but also to other factors, among which is ischaemia-reperfusion injury. Interestingly, increasing evidence points to the lectin pathway as a possible player in ischaemia-reperfusion injury, showing that the lectin pathway contributes to the increased inflammation, tissue damage and necrosis in ischaemia-reperfusion injury, together with other mechanisms. $^{109-111}$ This is supported by several animal studies which report smaller infarct size and improved functional outcome in MBL- or MASP-2-deficient mice after cerebral $^{107,112-114}$ or myocardial ${ }^{105,109,115-117}$ ischaemia-reperfusion injury. This association could be a possible explanation for the association between MBL and unfavourable outcome in stroke observed in the present review. However, this does not explain why a similar association with unfavourable outcome after MI was not consistently observed.

In SLE patients, one well-conducted follow-up study demonstrated that low MBL genotype was associated with higher risk of arterial thrombotic events, ${ }^{99}$ but three other studies on SLE patients could not reproduce these findings. ${ }^{96-98}$ Two studies investigated associations between MBL and sepsis-related DIC ${ }^{103,104}$ and both reported higher MBL levels to be associated with more severe coagulation disturbances. However, one study was very small $(n=18),{ }^{103}$ while in the second study, only a discrete difference in MBL levels was observed between the DIC and non-DIC group, and MBL was not found to be an independent predictor of DIC in sepsis. ${ }^{104}$ Thus, the influence of the lectin pathway on coagulation and thrombosis risk in both SLE and sepsis remains uncertain.

We included both arterial and venous thrombosis in the present review, with the majority of included studies focusing on arterial thrombotic events. Although arterial and venous thrombosis include several common factors, the mechanisms behind them differ considerably. Coronary and cerebral artery thrombosis usually includes a component of atherosclerosis. This is a complex condition characterized by chronic low-grade inflammation with activation of several immune system components, ${ }^{118,119}$ which may have been on-going for a long period of time before the major thrombotic event takes place. Activated platelets are also a key component of atherosclerosis, as they are activated by oxidized LDL and activated endothelial cells in the atherosclerotic plaque. In turn, they activate and uphold inflammation by facilitating monocyte migration, activating neutrophils and secreting pro-inflammatory factors. ${ }^{120,121}$ Interestingly, cholesterol crystals in the atherosclerotic plaque may play a role in activating the lectin pathway directly, ${ }^{122}$ and in diabetic patients, altered endothelial 
glycosylation patterns may further cause MBL binding and lectin pathway activation. ${ }^{42}$ Venous thrombosis, on the other hand, is driven largely (though not exclusively) by activation of secondary haemostasis, and traditional risk factors are hypercoagulability, loss of endothelial integrity with tissue factor exposure and decreased blood flow or stasis. ${ }^{123}$ Hypercoagulability can be inherited, but one of the major risk factors for venous thrombosis is inflammation, potentially induced by bacterial infection, autoimmune disease and traumatic or surgical acute phase response. The inflammationinduced hypercoagulability is driven by pro-inflammatory cytokines such as interleukin- 6 and caused by an increased production of pro-coagulant factors such as tissue factor, fibrinogen, FVIII, von Willebrand factor and plasminogen activator inhibitor-1, as well as decreased production of the endogenous anti-coagulants, anti-thrombin protein $\mathrm{C}$ and S. ${ }^{123,124}$ The venous thrombosis is often an acute event in itself, but local inflammatory changes in the vessel can persist and lead to chronic venous disease. ${ }^{125,126}$

The lectin pathway is an interesting potential contributor to inflammation-driven hypercoagulability and thrombosis through direct activation by MASPs, as described in the introduction. Since there is considerable crosstalk and mutual activation between the coagulation system and the lectin pathway, they may well activate each other in thrombotic and inflammatory conditions and thereby uphold the inflammatory and hyper-coagulable response in a vicious cycle. This emerging concept of immunothrombosis-or thromboinflammation-has recently been discussed. ${ }^{123,127}$ However, it should be noted that since changes in both lectin pathway proteins and coagulation factors occur during the acute phase response, any observed correlation between plasma levels does not equal causation, but may simply indicate that an acute phase reaction is on-going. It should also be considered that although there is solid evidence that MASPs are able to induce clot formation in vitro, this occurs at a lower rate than thrombin-induced clot formation. ${ }^{52}$ Furthermore, MASP-1-induced fibrin clots were found to be less dense and with thicker fibres than thrombininduced clots. ${ }^{53}$ This type of clots has been found more susceptible to lysis. ${ }^{128}$ Thus, the lectin pathway may have not a merely pro-coagulant but also a modulatory effect on coagulation, which could be clinically important.

The strengths of the present review were that we assessed the literature systematically, searching both PubMed and Embase and using broad search terms to minimize the risk of overlooking relevant studies. We performed a formal quality assessment and found the vast majority of studies to be of good or fair quality, which strengthens the validity of their results and our conclusions. The majority of studies included clinical endpoints for thromboembolic disease. However, some limitations should be mentioned. The study populations and endpoints for thrombosis were heterogeneous, and only few studies on thromboembolic conditions other than CVE and stroke were identified. This limits the value of comparison across all the identified studies and makes it impossible to conclude on the significance of the lectin pathway in the development of thrombotic conditions in a broader clinical setting.
To conclude, the existing evidence indicates that lectin pathway activation is associated with poor outcome after ischaemic stroke. Furthermore, there is some evidence for involvement of the lectin pathway in CVEs, although the exact role of the lectin pathway in this setting is not yet fully elucidated. With regards to other thrombotic conditions, only sparse clinical evidence exists, and future studies in this field are warranted.

\section{Funding}

J.B.L. was supported by a grant from the Faculty of Health, Aarhus University and the Health Research Fund of the Central Denmark Region.

Conflict of Interest

None.

\section{References}

1 Esmon CT, Xu J, Lupu F. Innate immunity and coagulation. J Thromb Haemost 2011;9(Suppl 1):182-188

2 van der Poll T, Herwald $H$. The coagulation system and its function in early immune defense. Thromb Haemost 2014;112 (04):640-648

3 Oikonomopoulou K, Ricklin D, Ward PA, Lambris JD. Interactions between coagulation and complement-their role in inflammation. Semin Immunopathol 2012;34(01):151-165

4 Degn SE, Jensenius JC, Bjerre M. The lectin pathway and its implications in coagulation, infections and auto-immunity. Curr Opin Organ Transplant 2011;16(01):21-27

5 Degn SE, Thiel S, Jensenius JC. New perspectives on mannanbinding lectin-mediated complement activation. Immunobiology 2007;212(4-5):301-311

6 Garred P, Genster N, Pilely K, et al. A journey through the lectin pathway of complement-MBL and beyond. Immunol Rev 2016; 274(01):74-97

7 Matsushita M, Endo Y, Fujita T. Structural and functional overview of the lectin complement pathway: its molecular basis and physiological implication. Arch Immunol Ther Exp (Warsz) 2013;61(04):273-283

8 Dunkelberger JR, Song WC. Complement and its role in innate and adaptive immune responses. Cell Res 2010;20(01): 34-50

9 Ma YJ, Doni A, Hummelshøj T, et al. Synergy between ficolin-2 and pentraxin 3 boosts innate immune recognition and complement deposition. J Biol Chem 2009;284(41):28263-28275

10 Ma YJ, Doni A, Skjoedt MO, et al. Heterocomplexes of mannosebinding lectin and the pentraxins PTX3 or serum amyloid P component trigger cross-activation of the complement system. J Biol Chem 2011;286(05):3405-3417

$11 \mathrm{Ng}$ PM, Le Saux A, Lee CM, et al. C-reactive protein collaborates with plasma lectins to boost immune response against bacteria. EMBO J 2007;26(14):3431-3440

12 Zhang J, Yang L, Ang Z, et al. Secreted M-ficolin anchors onto monocyte transmembrane $G$ protein-coupled receptor 43 and cross talks with plasma C-reactive protein to mediate immune signaling and regulate host defense. J Immunol 2010;185(11): 6899-6910

13 Frederiksen PD, Thiel S, Larsen CB, Jensenius JC. M-ficolin, an innate immune defence molecule, binds patterns of acetyl groups and activates complement. Scand J Immunol 2005;62 (05):462-473

14 Matsushita M, Endo Y, Fujita T. Cutting edge: complementactivating complex of ficolin and mannose-binding lectin-associated serine protease. J Immunol 2000;164(05):2281-2284 
15 Luo F, Sun X, Wang Y, et al. Ficolin-2 defends against virulent mycobacteria tuberculosis infection in vivo, and its insufficiency is associated with infection in humans. PLoS One 2013;8(09): e73859

16 Thiel S, Holmskov U, Hviid L, Laursen SB, Jensenius JC. The concentration of the $\mathrm{C}$-type lectin, mannan-binding protein, in human plasma increases during an acute phase response. Clin Exp Immunol 1992;90(01):31-35

17 Dean MM, Minchinton RM, Heatley S, Eisen DP. Mannose binding lectin acute phase activity in patients with severe infection. J Clin Immunol 2005;25(04):346-352

18 Plovsing RR, Berg RM, Munthe-Fog L, et al. Alveolar recruitment of ficolin-3 in response to acute pulmonary inflammation in humans. Immunobiology 2016;221(05):690-697

19 Van Till JW, Boermeester MA, Modderman PW, et al. Variable mannose-binding lectin expression during postoperative acutephase response. Surg Infect (Larchmt) 2006;7(05):443-452

20 Ytting H, Christensen IJ, Basse L, et al. Influence of major surgery on the mannan-binding lectin pathway of innate immunity. Clin Exp Immunol 2006;144(02):239-246

21 Troldborg A, Hansen A, Hansen SW, Jensenius JC, StengaardPedersen K, Thiel S. Lectin complement pathway proteins in healthy individuals. Clin Exp Immunol 2017;188(01):138-147

22 Thiel S. Complement activating soluble pattern recognition molecules with collagen-like regions, mannan-binding lectin, ficolins and associated proteins. Mol Immunol 2007;44(16):3875-3888

23 Bronkhorst MW, Lomax MA, Vossen RH, Bakker J, Patka P, van Lieshout EM. Risk of infection and sepsis in severely injured patients related to single nucleotide polymorphisms in the lectin pathway. Br J Surg 2013;100(13):1818-1826

24 De Pascale G, Cutuli SL, Pennisi MA, Antonelli M. The role of mannose-binding lectin in severe sepsis and septic shock. Mediators Inflamm 2013;2013:625803

25 Eisen DP, Dean MM, Thomas P, et al. Low mannose-binding lectin function is associated with sepsis in adult patients. FEMS Immunol Med Microbiol 2006;48(02):274-282

26 Schlapbach LJ, Mattmann M, Thiel S, et al. Differential role of the lectin pathway of complement activation in susceptibility to neonatal sepsis. Clin Infect Dis 2010;51(02):153-162

27 Charchaflieh J, Rushbrook J, Worah S, Zhang M. Activated complement factors as disease markers for sepsis. Dis Markers 2015; 2015:382463

28 Munthe-Fog L, Hummelshøj T, Honoré C, Madsen HO, Permin H, Garred P. Immunodeficiency associated with FCN3 mutation and ficolin-3 deficiency. N Engl J Med 2009;360(25):2637-2644

29 Metzger ML, Michelfelder I, Goldacker S, et al. Low ficolin-2 levels in common variable immunodeficiency patients with bronchiectasis. Clin Exp Immunol 2015;179(02):256-264

30 Schlapbach LJ, Thiel S, Kessler U, Ammann RA, Aebi C, Jensenius JC. Congenital H-ficolin deficiency in premature infants with severe necrotising enterocolitis. Gut 2011;60(10):1438-1439

31 Boldt AB, Luz PR, Messias-Reason IJ. MASP2 haplotypes are associated with high risk of cardiomyopathy in chronic Chagas disease. Clin Immunol 2011;140(01):63-70

32 Boldt AB, Goeldner I, Stahlke ER, Thiel S, Jensenius JC, de MessiasReason IJ. Leprosy association with low MASP-2 levels generated by MASP2 haplotypes and polymorphisms flanking MAp19 exon 5. PLoS One 2013;8(07):e69054

33 Munye MM, Diaz-Font A, Ocaka L, et al. COLEC10 is mutated in $3 \mathrm{MC}$ patients and regulates early craniofacial development. PLoS Genet 2017;13(03):e1006679

34 Rooryck C, Diaz-Font A, Osborn DP, et al. Mutations in lectin complement pathway genes COLEC11 and MASP1 cause 3MC syndrome. Nat Genet 2011;43(03):197-203

35 Sirmaci A, Walsh T, Akay H, et al. MASP1 mutations in patients with facial, umbilical, coccygeal, and auditory findings of Carnevale, Malpuech, OSA, and Michels syndromes. Am J Hum Genet 2010;87(05):679-686
36 Jacobsen S, Garred P, Madsen HO, et al. Mannose-binding lectin gene polymorphisms are associated with disease activity and physical disability in untreated, anti-cyclic citrullinated peptidepositive patients with early rheumatoid arthritis. J Rheumatol 2009;36(04):731-735

37 Troelsen LN, Garred P, Jacobsen S. Mortality and predictors of mortality in rheumatoid arthritis-a role for mannose-binding lectin? J Rheumatol 2010;37(03):536-543

38 Ammitzboll CG, Thiel S, Ellingsen T, et al. Levels of lectin pathway proteins in plasma and synovial fluid of rheumatoid arthritis and osteoarthritis. Rheumatol Int 2012;32(05):1457-1463

39 Epp Boschmann S, Goeldner I, Tuon FF, Schiel W, Aoyama F, de Messias-Reason IJ. Mannose-binding lectin polymorphisms and rheumatoid arthritis: a short review and meta-analysis. Mol Immunol 2016;69:77-85

40 Troldborg A, Thiel S, Laska MJ, Deleuran B, Jensenius JC, Stengaard-Pedersen $\mathrm{K}$. Levels in plasma of the serine proteases and associated proteins of the lectin pathway are altered in patients with systemic lupus erythematosus. J Rheumatol 2015;42(06): 948-951

41 Hein E, Nielsen LA, Nielsen CT, et al. Ficolins and the lectin pathway of complement in patients with systemic lupus erythematosus. Mol Immunol 2015;63(02):209-214

42 Jenny L, Ajjan R, King R, Thiel S, Schroeder V. Plasma levels of mannan-binding lectin-associated serine proteases MASP-1 and MASP-2 are elevated in type 1 diabetes and correlate with glycaemic control. Clin Exp Immunol 2015;180(02):227-232

43 Axelgaard E, Østergaard JA, Thiel S, Hansen TK. Diabetes is associated with increased autoreactivity of mannan-binding lectin. J Diabetes Res 2017;2017:6368780

44 Best LG, Davidson M, North KE, et al. Prospective analysis of mannose-binding lectin genotypes and coronary artery disease in American Indians: the Strong Heart Study. Circulation 2004; 109(04):471-475

45 Hertle E, Arts IC, van der Kallen CJ, et al. Distinct longitudinal associations of MBL, MASP-1, MASP-2, MASP-3, and MAp44 with endothelial dysfunction and intima-media thickness: the Cohort on Diabetes and Atherosclerosis Maastricht (CODAM) Study. Arterioscler Thromb Vasc Biol 2016;36(06):1278-1285

46 Ytting H, Christensen IJ, Thiel S, Jensenius JC, Nielsen HJ. Pre- and postoperative levels in serum of mannan-binding lectin associated serine protease-2 -a prognostic marker in colorectal cancer. Hum Immunol 2008;69(07):414-420

47 Storm L, Christensen IJ, Jensenius JC, Nielsen HJ, Thiel S; Danish Study Group on Early Detection of Colorectal Cancer. Evaluation of complement proteins as screening markers for colorectal cancer. Cancer Immunol Immunother 2015;64(01):41-50

48 Swierzko AS, Szala A, Sawicki S, et al. Mannose-binding lectin (MBL) and MBL-associated serine protease-2 (MASP-2) in women with malignant and benign ovarian tumours. Cancer Immunol Immunother 2014;63(11):1129-1140

49 Ambrus G, Gál P, Kojima M, et al. Natural substrates and inhibitors of mannan-binding lectin-associated serine protease-1 and -2: a study on recombinant catalytic fragments. J Immunol 2003;170(03):1374-1382

50 Presanis JS, Hajela K, Ambrus G, Gál P, Sim RB. Differential substrate and inhibitor profiles for human MASP-1 and MASP2. Mol Immunol 2004;40(13):921-929

51 Dobó J, Harmat V, Beinrohr L, Sebestyén E, Závodszky P, Gál P. MASP-1, a promiscuous complement protease: structure of its catalytic region reveals the basis of its broad specificity. J Immunol 2009;183(02):1207-1214

52 Krarup A, Gulla KC, Gál P, Hajela K, Sim RB. The action of MBLassociated serine protease 1 (MASP1) on factor XIII and fibrinogen. Biochim Biophys Acta 2008;1784(09):1294-1300

53 Hess K, Ajjan R, Phoenix F, Dobó J, Gál P, Schroeder V. Effects of MASP-1 of the complement system on activation of coagulation factors and plasma clot formation. PLoS One 2012;7(04):e35690 
54 Hajela K, Kojima M, Ambrus G, et al. The biological functions of MBL-associated serine proteases (MASPs). Immunobiology 2002;205(4-5):467-475

55 Gulla KC, Gupta K, Krarup A, et al. Activation of mannan-binding lectin-associated serine proteases leads to generation of a fibrin clot. Immunology 2010;129(04):482-495

56 Jenny L, Dobó J, Gál P, Schroeder V. MASP-1 induced clotting-the first model of prothrombin activation by MASP-1. PLoS One 2015;10(12):e0144633

57 Jenny L, Dobó J, Gál P, Schroeder V. MASP-1 of the complement system promotes clotting via prothrombin activation. Mol Immunol 2015;65(02):398-405

58 Jenny L, Dobó J, Gál P, Pál G, Lam WA, Schroeder V. MASP-1 of the complement system enhances clot formation in a microvascular whole blood flow model. PLoS One 2018;13(01):e0191292

59 Krarup A, Wallis R, Presanis JS, Gál P, Sim RB. Simultaneous activation of complement and coagulation by MBL-associated serine protease 2. PLoS One 2007;2(07):e623

60 Endo Y, Nakazawa N, Iwaki D, Takahashi M, Matsushita M, Fujita $\mathrm{T}$. Interactions of ficolin and mannose-binding lectin with fibrinogen/fibrin augment the lectin complement pathway. J Innate Immun 2010;2(01):33-42

61 Kozarcanin H, Lood C, Munthe-Fog L, et al. The lectin complement pathway serine proteases (MASPs) represent a possible crossroad between the coagulation and complement systems in thromboinflammation. J Thromb Haemost 2016;14(03):531-545

62 Keizer MP, Pouw RB, Kamp AM, et al. TFPI inhibits lectin pathway of complement activation by direct interaction with MASP-2. Eur J Immunol 2015;45(02):544-550

63 AMSTAR-Assessing the Methodological Quality of Systematic Reviews; 2015. Available at: https://amstar.ca/. Accessed August 29, 2017

64 Quality Assessment Tool for Observational Cohort and CrossSectional Studies; 2014. Available at: https://www.nhlbi.nih.gov/ health-pro/guidelines/in-develop/cardiovascular-risk-reduction/ tools/cohort. Accessed May 1, 2017

65 Quality Assessment of Case-Control Studies; 2014. Available at: https://www.nhlbi.nih.gov/health-pro/guidelines/in-develop/ cardiovascular-risk-reduction/tools/case-control

66 Poppelaars F, Gaya da Costa M, Berger SP, et al. Strong predictive value of mannose-binding lectin levels for cardiovascular risk of hemodialysis patients. J Transl Med 2016;14(01):236

67 Siezenga MA, Shaw PK, Daha MR, Rabelink TJ, Berger SP. Low mannose-binding lectin (MBL) genotype is associated with future cardiovascular events in type 2 diabetic South Asians. A prospective cohort study. Cardiovasc Diabetol 2011;10:60

68 Troelsen LN, Garred P, Madsen HO, Jacobsen S. Genetically determined high serum levels of mannose-binding lectin and agalactosyl IgG are associated with ischemic heart disease in rheumatoid arthritis. Arthritis Rheum 2007;56(01):21-29

69 Berger SP, Roos A, Mallat MJ, et al. Low pretransplantation mannose-binding lectin levels predict superior patient and graft survival after simultaneous pancreas-kidney transplantation. J Am Soc Nephrol 2007;18(08):2416-2422

70 Keller TT, van Leuven SI, Meuwese MC, et al. Serum levels of mannose-binding lectin and the risk of future coronary artery disease in apparently healthy men and women. Arterioscler Thromb Vasc Biol 2006;26(10):2345-2350

71 Saevarsdottir S, Oskarsson OO, Aspelund T, et al. Mannan binding lectin as an adjunct to risk assessment for myocardial infarction in individuals with enhanced risk. J Exp Med 2005;201(01): 117-125

72 Vengen IT, Madsen HO, Garred P, Platou C, Vatten L, Videm V. Mannose-binding lectin deficiency is associated with myocardial infarction: the HUNT2 study in Norway. PLoS One 2012;7 (07):e42113

73 Vengen IT, Enger TB, Videm V, Garred P. Pentraxin 3, ficolin-2 and lectin pathway associated serine protease MASP-3 as early predictors of myocardial infarction - the HUNT2 study. Sci Rep 2017;7:43045

74 Pesonen E, Hallman M, Sarna S, et al. Mannose-binding lectin as a risk factor for acute coronary syndromes. Ann Med 2009;41(08): 591-598

75 Hansen TK, Tarnow L, Thiel S, et al. Association between mannose-binding lectin and vascular complications in type 1 diabetes. Diabetes 2004;53(06):1570-1576

76 Zhang M, Hou YJ, Cavusoglu E, et al. MASP-2 activation is involved in ischemia-related necrotic myocardial injury in humans. Int J Cardiol 2013;166(02):499-504

77 Mellbin LG, Hamsten A, Malmberg K, et al. Mannose-binding lectin genotype and phenotype in patients with type 2 diabetes and myocardial infarction: a report from the DIGAMI 2 trial. Diabetes Care 2010;33(11):2451-2456

78 Trendelenburg M, Theroux P, Stebbins A, Granger C, Armstrong $\mathrm{P}$, Pfisterer M. Influence of functional deficiency of complement mannose-binding lectin on outcome of patients with acute ST-elevation myocardial infarction undergoing primary percutaneous coronary intervention. Eur Heart J 2010;31(10): 1181-1187

79 Haahr-Pedersen S, Bjerre M, Flyvbjerg A, et al. Level of complement activity predicts cardiac dysfunction after acute myocardial infarction treated with primary percutaneous coronary intervention. J Invasive Cardiol 2009;21(01):13-19

80 Collard CD, Shernan SK, Fox AA, et al. The MBL2 'LYQA secretor' haplotype is an independent predictor of postoperative myocardial infarction in whites undergoing coronary artery bypass graft surgery. Circulation 2007;116(11, Suppl):I106-I112

81 Ueland T, Espevik T, Kjekshus J, et al. Mannose binding lectin and soluble Toll-like receptor 2 in heart failure following acute myocardial infarction. J Card Fail 2006;12(08):659-663

82 Limnell V, Aittoniemi J, Vaarala O, et al. Association of mannanbinding lectin deficiency with venous bypass graft occlusions in patients with coronary heart disease. Cardiology 2002;98(03): 123-126

83 Schoos MM, Munthe-Fog L, Skjoedt MO, et al. Association between lectin complement pathway initiators, C-reactive protein and left ventricular remodeling in myocardial infarction-a magnetic resonance study. Mol Immunol 2013;54(3-4):408-414

84 Holt CB, Thiel S, Munk K, Østergaard JA, Bøtker HE, Hansen TK. Association between endogenous complement inhibitor and myocardial salvage in patients with myocardial infarction. Eur Heart J Acute Cardiovasc Care 2014;3(01):3-9

85 Mellbin LG, Bjerre M, Thiel S, Hansen TK. Complement activation and prognosis in patients with type 2 diabetes and myocardial infarction: a report from the DIGAMI 2 trial. Diabetes Care 2012; 35(04):911-917

86 Kouchaki E, Babamohammadi A, Nikoueinejad H, Sehat M. Association of serum levels of pentraxin-3, M-ficolin, and surfactant protein A with the severity of ischemic stroke. Iran J Allergy Asthma Immunol 2017;16(02):140-146

87 Huang J, Ma X, Li Q et al. Serum mannose-binding lectin levels in patients with ischemic stroke. Int J Clin Exp Med 2016;9(08): 16332-16338

88 Zangari R, Zanier ER, Torgano G, et al; LEPAS group. Early ficolin1 is a sensitive prognostic marker for functional outcome in ischemic stroke. J Neuroinflammation 2016;13:16

89 Song FY, Wu MH, Zhu LH, Zhang ZQ Qi QD, Lou CL. Elevated serum mannose-binding lectin levels are associated with poor outcome after acute ischemic stroke in patients with type 2 diabetes. Mol Neurobiol 2015;52(03):1330-1340

90 Zhang ZG, Wang C, Wang J, et al. Prognostic value of mannosebinding lectin: 90-day outcome in patients with acute ischemic stroke. Mol Neurobiol 2015;51(01):230-239

91 Wang ZY, Sun ZR, Zhang LM. The relationship between serum mannose-binding lectin levels and acute ischemic stroke risk. Neurochem Res 2014;39(02):248-253 
92 Füst G, Munthe-Fog L, Illes Z, et al. Low ficolin-3 levels in early follow-up serum samples are associated with the severity and unfavorable outcome of acute ischemic stroke. J Neuroinflammation 2011;8:185

93 Osthoff M, Katan M, Fluri F, et al. Mannose-binding lectin deficiency is associated with smaller infarction size and favorable outcome in ischemic stroke patients. PLoS One 2011;6(06): e21338

94 Cervera A, Planas AM, Justicia C, et al. Genetically-defined deficiency of mannose-binding lectin is associated with protection after experimental stroke in mice and outcome in human stroke. PLoS One 2010;5(02):e8433

95 Frauenknecht V, Thiel S, Storm L, et al. Plasma levels of mannanbinding lectin (MBL)-associated serine proteases (MASPs) and MBL-associated protein in cardio- and cerebrovascular diseases. Clin Exp Immunol 2013;173(01):112-120

96 Jönsen A, Gullstrand B, Güner N, et al. Genetically determined mannan-binding lectin deficiency is of minor importance in determining susceptibility to severe infections and vascular organ damage in systemic lupus erythematosus. Lupus 2007; 16(04):245-253

97 Font J, Ramos-Casals M, Brito-Zerón P, et al. Association of mannose-binding lectin gene polymorphisms with antiphospholipid syndrome, cardiovascular disease and chronic damage in patients with systemic lupus erythematosus. Rheumatology (Oxford) 2007;46(01):76-80

98 Calvo-Alén J, Alarcón GS, Tew MB, et al; LUMINA Study Group. Systemic lupus erythematosus in a multiethnic US cohort: XXXIV. Deficient mannose-binding lectin exon 1 polymorphisms are associated with cerebrovascular but not with other arterial thrombotic events. Arthritis Rheum 2006;54(06): 1940-1945

99 Øhlenschlaeger T, Garred P, Madsen HO, Jacobsen S. Mannosebinding lectin variant alleles and the risk of arterial thrombosis in systemic lupus erythematosus. N Engl J Med 2004;351(03): 260-267

100 Lv W, Wang L, Duan Q, et al. Characteristics of the complement system gene expression deficiency in patients with symptomatic pulmonary embolism. Thromb Res 2013;132(01):e54-e57

101 Merlen C, Bonnefoy A, Wagner E, et al. L-Asparaginase lowers plasma antithrombin and mannan-binding-lectin levels: impact on thrombotic and infectious events in children with acute lymphoblastic leukemia. Pediatr Blood Cancer 2015;62(08): 1381-1387

102 Takahashi K, Ohtani K, Larvie M, et al. Elevated plasma CL-K1 level is associated with a risk of developing disseminated intravascular coagulation (DIC). J Thromb Thrombolysis 2014;38(03): 331-338

103 Sprong T, Mollnes TE, Neeleman C, et al. Mannose-binding lectin is a critical factor in systemic complement activation during meningococcal septic shock. Clin Infect Dis 2009;49(09): 1380-1386

104 Zhao X, Chen YX, Li CS. Predictive value of the complement system for sepsis-induced disseminated intravascular coagulation in septic patients in emergency department. J Crit Care 2015;30(02):290-295

105 Pavlov VI, Skjoedt MO, Siow Tan Y, Rosbjerg A, Garred P, Stahl GL. Endogenous and natural complement inhibitor attenuates myocardial injury and arterial thrombogenesis. Circulation 2012;126 (18):2227-2235

106 Takahashi K, Chang WC, Takahashi M, et al. Mannose-binding lectin and its associated proteases (MASPs) mediate coagulation and its deficiency is a risk factor in developing complications from infection, including disseminated intravascular coagulation. Immunobiology 2011;216(1-2):96-102

107 de la Rosa X, Cervera A, Kristoffersen AK, et al. Mannose-binding lectin promotes local microvascular thrombosis after transient brain ischemia in mice. Stroke 2014;45(05):1453-1459
108 Fumagalli S, De Simoni MG. Lectin complement pathway and its bloody interactions in brain ischemia. Stroke 2016;47(12): 3067-3073

109 Jordan JE, Montalto MC, Stahl GL. Inhibition of mannose-binding lectin reduces postischemic myocardial reperfusion injury. Circulation 2001;104(12):1413-1418

110 Hart ML, Ceonzo KA, Shaffer LA, et al. Gastrointestinal ischemiareperfusion injury is lectin complement pathway dependent without involving C1q. J Immunol 2005;174(10):6373-6380

111 Busche MN, Pavlov V, Takahashi K, Stahl GL. Myocardial ischemia and reperfusion injury is dependent on both IgM and mannosebinding lectin. Am J Physiol Heart Circ Physiol 2009;297(05): H1853-H1859

112 Ducruet AF, Sosunov SA, Zacharia BE, et al. The neuroprotective effect of genetic mannose-binding lectin deficiency is not sustained in the sub-acute phase of stroke. Transl Stroke Res 2011;2 (04):588-599

113 Orsini F, Villa P, Parrella S, et al. Targeting mannose-binding lectin confers long-lasting protection with a surprisingly wide therapeutic window in cerebral ischemia. Circulation 2012;126 (12):1484-1494

114 Orsini F, Chrysanthou E, Dudler T, et al. Mannan binding lectinassociated serine protease-2 (MASP-2) critically contributes to post-ischemic brain injury independent of MASP-1. J Neuroinflammation 2016;13(01):213

115 Walsh MC, Bourcier T, Takahashi K, et al. Mannose-binding lectin is a regulator of inflammation that accompanies myocardial ischemia and reperfusion injury. J Immunol 2005;175(01):541-546

116 La Bonte LR, Dokken B, Davis-Gorman G, Stahl GL, McDonagh PF. The mannose-binding lectin pathway is a significant contributor to reperfusion injury in the type 2 diabetic heart. Diab Vasc Dis Res 2009;6(03):172-180

117 Schwaeble WJ, Lynch NJ, Clark JE, et al. Targeting of mannanbinding lectin-associated serine protease- 2 confers protection from myocardial and gastrointestinal ischemia/reperfusion injury. Proc Natl Acad Sci U S A 2011;108(18):7523-7528

118 Pant S, Deshmukh A, Gurumurthy GS, et al. Inflammation and atherosclerosis-revisited. J Cardiovasc Pharmacol Ther 2014;19 (02):170-178

119 Viola J, Soehnlein O. Atherosclerosis - a matter of unresolved inflammation. Semin Immunol 2015;27(03):184-193

120 Langer HF, Gawaz M. Platelet-vessel wall interactions in atherosclerotic disease. Thromb Haemost 2008;99(03):480-486

121 Lisman T. Platelet-neutrophil interactions as drivers of inflammatory and thrombotic disease. Cell Tissue Res 2018;371(03): 567-576

122 Pilely K, Rosbjerg A, Genster N, et al. Cholesterol crystals activate the lectin complement pathway via ficolin-2 and mannosebinding lectin: implications for the progression of atherosclerosis. J Immunol 2016;196(12):5064-5074

123 Vazquez-Garza E, Jerjes-Sanchez C, Navarrete A, Joya-Harrison J, Rodriguez D. Venous thromboembolism: thrombosis, inflammation, and immunothrombosis for clinicians. J Thromb Thrombolysis 2017;44(03):377-385

124 Levi M, Schultz M, van der Poll T. Sepsis and thrombosis. Semin Thromb Hemost 2013;39(05):559-566

125 Takase S, Schmid-Schönbein G, Bergan JJ. Leukocyte activation in patients with venous insufficiency. J Vasc Surg 1999;30(01): 148-156

126 Takase S, Bergan JJ, Schmid-Schönbein G. Expression of adhesion molecules and cytokines on saphenous veins in chronic venous insufficiency. Ann Vasc Surg 2000;14(05):427-435

127 Ekdahl KN, Teramura Y, Hamad OA, et al. Dangerous liaisons: complement, coagulation, and kallikrein/kinin cross-talk act as a linchpin in the events leading to thromboinflammation. Immunol Rev 2016;274(01):245-269

128 Gabriel DA, Muga K, Boothroyd EM. The effect of fibrin structure on fibrinolysis. J Biol Chem 1992;267(34):24259-24263 
129 Litzman J, Freiberger T, Grimbacher B, et al. Mannose-binding lectin gene polymorphic variants predispose to the development of bronchopulmonary complications but have no influence on other clinical and laboratory symptoms or signs of common variable immunodeficiency. Clin Exp Immunol 2008;153(03):324-330

130 Luo J, Xu F, Lu GJ, Lin HC, Feng ZC. Low mannose-binding lectin (MBL) levels and MBL genetic polymorphisms associated with the risk of neonatal sepsis: an updated meta-analysis. Early Hum Dev 2014;90(10):557-564

131 Peterslund NA, Koch C, Jensenius JC, Thiel S. Association between deficiency of mannose-binding lectin and severe infections after chemotherapy. Lancet 2001;358(9282):637-638

132 Mullighan CG, Heatley S, Doherty K, et al. Mannose-binding lectin gene polymorphisms are associated with major infection following allogeneic hemopoietic stem cell transplantation. Blood 2002;99(10):3524-3529

133 Garcia-Laorden MI, Sole-Violan J, Rodriguez de Castro F, et al. Mannose-binding lectin and mannose-binding lectin-associated serine protease 2 in susceptibility, severity, and outcome of pneumonia in adults. J Allergy Clin Immunol 2008;122(02): 368-374, 374.e1-374.e2

134 Kruse C, Rosgaard A, Steffensen R, Varming K, Jensenius JC, Christiansen OB. Low serum level of mannan-binding lectin is a determinant for pregnancy outcome in women with recurrent spontaneous abortion. Am J Obstet Gynecol 2002;187(05): $1313-1320$

135 Christiansen OB, Kilpatrick DC, Souter V, Varming K, Thiel S, Jensenius JC. Mannan-binding lectin deficiency is associated with unexplained recurrent miscarriage. Scand J Immunol 1999;49(02):193-196

136 Kilpatrick DC, Bevan BH, Liston WA. Association between mannan binding protein deficiency and recurrent miscarriage. Hum Reprod 1995;10(09):2501-2505

137 Munthe-Fog L, Hummelshoj T, Honoré C, et al. Variation in FCN1 affects biosynthesis of ficolin-1 and is associated with outcome of systemic inflammation. Genes Immun 2012;13 (07):515-522
138 Ammitzbøll CG, Kjær TR, Steffensen R, et al. Non-synonymous polymorphisms in the FCN1 gene determine ligand-binding ability and serum levels of M-ficolin. PLoS One 2012;7(11):e50585

139 Boldt AB, Sanchez MI, Stahlke ER, et al. Susceptibility to leprosy is associated with M-ficolin polymorphisms. J Clin Immunol 2013; 33(01):210-219

140 Munthe-Fog L, Hummelshøj T, Hansen BE, et al. The impact of FCN2 polymorphisms and haplotypes on the Ficolin-2 serum levels. Scand J Immunol 2007;65(04):383-392

141 Bayarri-Olmos R, Hansen S, Henriksen ML, et al. Genetic variation of COLEC10 and COLEC11 and association with serum levels of collectin liver 1 (CL-L1) and collectin kidney 1 (CL-K1). PLoS One 2015;10(02):e0114883

142 Antony JS, Ojurongbe O, Kremsner PG, Velavan TP. Lectin complement protein Collectin 11 (CL-K1) and susceptibility to urinary schistosomiasis. PLoS Negl Trop Dis 2015;9(03):e0003647

143 Troegeler A, Lugo-Villarino G, Hansen S, et al. Collectin CL-LK is a novel soluble pattern recognition receptor for mycobacterium tuberculosis. PLoS One 2015;10(07):e0132692

144 Beltrame MH, Boldt AB, Catarino SJ, et al. MBL-associated serine proteases (MASPs) and infectious diseases. Mol Immunol 2015; 67(01):85-100

145 Stengaard-Pedersen K, Thiel S, Gadjeva M, et al. Inherited deficiency of mannan-binding lectin-associated serine protease 2 . N Engl J Med 2003;349(06):554-560

146 Sokolowska A, Szala A, St Swierzko A, et al. Mannan-binding lectin-associated serine protease-2 (MASP-2) deficiency in two patients with pulmonary tuberculosis and one healthy control. Cell Mol Immunol 2015;12(01):119-121

147 García-Laorden MI, García-Saavedra A, de Castro FR, et al. Low clinical penetrance of mannose-binding lectin-associated serine protease 2 deficiency. J Allergy Clin Immunol 2006;118(06): 1383-1386

148 Skjødt M-O, Munthe-Fog L, Hansen KM, Garred P. Inhibition of the coagulation system by the complement regulator MBL/ Ficolin-Associated Protein-1 (MAP-1). Molecular Immunology 2014;61(02):219 